Article

\title{
Sustainable Biodiesel Synthesis from Honne-Rubber-Neem Oil Blend with a Novel Mesoporous Base Catalyst Synthesized from a Mixture of Three Agrowastes
}

\author{
Olayomi A. Falowo ${ }^{1,+}$, Tunde V. Ojumu ${ }^{2} \mathbb{D}$, Omoniyi Pereao ${ }^{2} \mathbb{D}$ and Eriola Betiku 1,3,*(D) \\ 1 Biochemical Engineering Laboratory, Department of Chemical Engineering, Obafemi Awolowo University, \\ Ile-Ife 220005, Osun State, Nigeria; falowo86@yahoo.com \\ 2 Department of Chemical Engineering, Cape Peninsula University of Technology, Bellville, Symphony Way, \\ Bellville, Cape Town 7535, South Africa; OjumuT@cput.ac.za (T.V.O.); pereaokola@gmail.com (O.P.) \\ 3 Department of Biological Sciences, Florida Agricultural and Mechanical Engineering University, Tallahassee, \\ FL 32307, USA \\ * Correspondence: ebetiku@oauife.edu.ng or eriola.betiku@famu.edu \\ † Present address: Department of Chemical Engineering, Landmark University, Omu-Aran 251101, \\ Kwara State, Nigeria.
}

Received: 29 November 2019; Accepted: 29 December 2019; Published: 5 February 2020

\begin{abstract}
Application of solid catalysts synthesized from agricultural wastes provides an environmentally benign and low-cost process path to synthesize biodiesel. An ash containing an equal mixture of cocoa pod husk, plantain peel and kola nut pod husk ashes (CPK) was obtained by open combustion of each of the biomass in air and calcined at $500{ }^{\circ} \mathrm{C}$ for $4 \mathrm{~h}$. The calcined CPK ash was characterized to determine its catalytic potential. Two-level transesterification technique was used to synthesize biodiesel using the developed catalyst. The process parameters involved were optimized for the microwave-aided transesterification of a blend of honne, rubber seed and neem oils in a volumetric ratio of 20:20:60, respectively. The study showed that the ash derived from combination of the biomass wastes provided a catalyst which consists all necessary catalytic ingredients in their relative abundance. The calcined CPK consists of $47.67 \%$ of potassium, $5.56 \%$ calcium and $4.21 \%$ magnesium attesting to its heterogenous status. The physisorption isotherms reveals that it was dominantly mesoporous in structure and made up of nanoparticles. A maximum of $98.45 \mathrm{wt}$ \% biodiesel was obtained from a MeOH:oil blend of 12:1, CPK concentration of 1.158 wt.\% and reaction time of 6 min under microwave irradiation. The quality of the synthesized biodiesel satisfied the requirements stipulated by standard specifications. Thus, this work demonstrates that a blend of agrowastes and mixtures of non-edible oils could be used to synthesize good quality and sustainable biodiesel that can replace fossil diesel.
\end{abstract}

Keywords: heterogenous catalyst; biodiesel; agrowaste; microwave; optimization; transesterification

\section{Introduction}

Active research in renewable and nonpolluting energy sources has taken center stage in a bid to enhance energy security and prevent environmental degradation. Presently, fuel derived from fossil sources is the socioeconomic mainstay of several countries in the world. However, concerns such as unstable petroleum price, depletion of oil reserves and emission of greenhouse gases are discouraging long-term usage of petro-diesel worldwide [1]. Total or partial replacement of fossil-derived fuel with clean, economically feasible, sustainable and renewable energy sources has become imperative towards achieving balance in energy security and environmental protection in any developing economy. 
Biodiesel is a renewable fuel having remarkable features and can serve as an alternative to fossil diesel. Transesterification of the triglycerides found in vegetable oil or animal fat or lipids from algae and methanol or ethanol in the presence of a catalyst is by far the most widely applied technique for biodiesel synthesis. Generally, biodiesel synthesis via transesterification employs catalysts that can be acid, alkali or enzyme [2]. The free fatty acid (FFA) level in oils primarily determines the choice of catalyst to be used for the process [3].

Homogeneous and heterogeneous catalysis have been applied to transesterification of oils to obtain biodiesel. Homogeneous catalysis has several advantages, including low price, abundant raw materials, shorter reaction time, high catalytic activities and moderate operating conditions [4,5]. In spite of these benefits, homogeneous catalysis is not without shortcomings which limits its continuous application in biodiesel production. Homogenous alkali catalysts are highly hygroscopic; they absorb water during storage [5]. Besides, purification steps require several washes and removing the traces of $\mathrm{Na} / \mathrm{K}$ together with the glycerol from the biodiesel becomes increasingly difficult. A lot of water required in washing and consequent wastewater treatment cost leads to high production cost [6]. To counter these negative effects posed by this type of catalysts, eco-friendly materials are used to synthesize heterogenous solid catalysts $[7,8]$. Heterogenous catalysis offers several advantages including recyclability, easy separation, non-corrosiveness, higher selectivity, environmentally benign nature and longer catalyst life $[4,5]$. Exploitation of wastes for catalyst development in biodiesel production could be used to mitigate environmental damage $[9,10]$. Currently, a lot of effort has been put into development of heterogeneous solid acid and alkali catalysts for biodiesel synthesis which may help reduce overall production costs. Evidence from several works indicate that this approach has been successfully applied for biodiesel production. Sources of biomass-derived catalysts include waste shells, biomass ashes, activated carbon-supported catalysts, animal bones and waste coral [10-15].

The belief that heterogenous catalysis is limited by mass transfer rate, low active site and leaching may have been exaggerated and attaching a solid catalyst to a support will increase the price of biodiesel. It should be noted that loading a catalyst on a support incurs extra cost, thereby further increasing the total production cost. In contrast, biodiesel production using different heterogenous alkali catalysts prepared by calcination without catalyst support showed high yields. For instance, conversion of soybean oil to biodiesel at a temperature of $65^{\circ} \mathrm{C}$, reaction time of $25 \mathrm{~min}, \mathrm{MeOH}$ :oil of 12:1 and $7 \mathrm{wt} . \%$ amount of a catalyst from waste Brassica nigra plant gave $98.79 \mathrm{wt} . \%$ yield [13]. Betiku et al. [7] reported biodiesel yield of $98.5 \mathrm{wt} . \%$ using calcined banana peel as catalyst under the reaction conditions of temperature of $65^{\circ} \mathrm{C}$, time of $69.02 \mathrm{~min}$, MeOH:oil of 7.6:1 and catalyst amount of $2.75 \mathrm{wt} . \%$ from Napoleon's plume oil. Biodiesel produced from Ceiba pentandra oil gave a maximum yield of $98.69 \pm 0.18$ $\mathrm{wt} . \%$ using calcined banana peduncle ash of $1.978 \mathrm{wt} . \%$ at reaction temperature of $65^{\circ} \mathrm{C}$, time of $1 \mathrm{~h}$ and $\mathrm{MeOH}$ :oil of 9.20:1 [14]. Transesterification of soybean oil in the presence of banana peel ash at room temperature, reaction time of [14], MeOH:oil of 6:1 and catalyst amount of $0.7 \mathrm{wt} . \%$ gave a biodiesel yield of $98.95 \%$ [16]. Several heterogenous catalysts with high catalytic activities have been developed at suitable calcination temperatures from waste materials. Calcination of ash is a cost-effective approach in producing catalyst [9]. Although carbon-based solid catalysts have been touted as the ideal catalyst for transesterification process; costs incurred due to high carbonization temperature and unwanted chemical reactions due to functionalization of the carbonaceous substance have restricted its application on a large scale. Hence, calcination of biomass ashes could offer a simpler and cost-effective means in synthesizing catalyst with high catalytic behavior for transesterification processes.

Proximate analysis has revealed that agricultural wastes such as kola nut pod husk, plantain peel (ripe and unripe) and cocoa pod husk are potential raw materials for industrial applications [17]. Heterogeneous biobase catalysts for the conversion of vegetable oils to biodiesel have been synthesized separately from kola nut pod husks [18,19], cocoa pod husks [20,21] and plantain peels [22,23] (Table 1), but the catalytic activity of the ash obtained from the mixture of these wastes as a potential biobase catalyst for the transesterification reaction has not been reported. Mixtures of oils viz. edible, inedible and waste cooking oils have been exploited for biodiesel synthesis. 
Table 1. Solid based-heterogeneous catalyst derived from biomass.

\begin{tabular}{|c|c|c|c|c|c|c|c|c|c|c|}
\hline \multirow{2}{*}{ Biowaste } & \multicolumn{3}{|c|}{ Calcination Condition } & \multicolumn{5}{|c|}{ Transesterification Condition } & \multirow{2}{*}{$\begin{array}{l}\text { Biodiesel } \\
\text { Yield }\end{array}$} & \multirow{2}{*}{ Reference } \\
\hline & $\begin{array}{l}\text { Heat } \\
\left({ }^{\circ} \mathrm{C}\right)\end{array}$ & Time (h) & Main Metallic Content & Oil & $\begin{array}{c}\text { MeOH:Oil } \\
\text { Molar Ratio }\end{array}$ & $\begin{array}{l}\text { Catalyst } \\
\text { (wt.\%) }\end{array}$ & $\begin{array}{l}\text { Temperature } \\
\left({ }^{\circ} \mathrm{C}\right)\end{array}$ & $\begin{array}{l}\text { Time } \\
(\mathrm{min})\end{array}$ & & \\
\hline Cocoa pod husk & 700 & 4 & $\mathrm{~K}(59.2 \%), \mathrm{Mg}(3 \%)$ & Neem & $0.73 v / v$ & 0.65 & 65 & 57 & 99.3 & [21] \\
\hline Cocoa pod husk & 650 & 4 & - & Soybean & $6: 1$ & 1 & 60 & 120 & 91.4 & [20] \\
\hline Plantain peel (ripe) & 700 & 4 & $\mathrm{~K}(51.02 \%), \mathrm{Mg}(1.15 \%)$ & Neem & $0.73 v / v$ & 0.65 & 65 & 57 & 99.2 & [23] \\
\hline $\begin{array}{l}\text { Plantain peel } \\
\text { (unripe) }\end{array}$ & 500 & 3.5 & $\begin{array}{c}\mathrm{K}(54.73 \%), \mathrm{Ca}(1.13 \%) \\
\mathrm{Al}(3.42 \%)\end{array}$ & Yellow oleander & $0.33 v / v$ & 3 & 60 & 90 & 95.25 & [22] \\
\hline Kola nut husk & 500 & 4 & $\begin{array}{c}\mathrm{K}(47.14 \%), \mathrm{Ca}(7.59 \%) \\
\mathrm{Mg}(5.32 \%)\end{array}$ & Kariya & $6: 1$ & 3 & 65 & 75 & 98.67 & [18] \\
\hline Kola nut husk & 600 & 3 & $\begin{array}{c}\mathrm{K}(33.914 \%), \mathrm{Ca} \\
25.382 \%), \mathrm{Mg}(12.398 \%) \\
\mathrm{K}(99.73 \%), \mathrm{Ca}(0.03 \%),\end{array}$ & Yellow oleander & $6: 1$ & 1.5 & 60 & 90 & 84.5 & [19] \\
\hline Banana peel & 700 & 4 & $\begin{array}{c}\mathrm{Na}(0.19 \%), \mathrm{Mg}(0.03 \%) \\
\mathrm{Fe}(0.01 \%)\end{array}$ & Napoleon's plume & $7.6: 1$ & 2.75 & 65 & 69.02 & 98.5 & [7] \\
\hline Banana peel & $\begin{array}{l}\text { Open air } \\
\text { burning }\end{array}$ & NS & $\begin{array}{l}\mathrm{K}(70.06 \%), \mathrm{Ca}(9.54 \%) \\
\mathrm{Mg}(1.78 \%), \mathrm{Fe}(1.49 \%)\end{array}$ & Soybean & $6: 1$ & 0.7 & $\begin{array}{c}\text { Room } \\
\text { temperature }\end{array}$ & 240 & $98.95 \%$ & [16] \\
\hline Banana peduncle & 700 & 4 & $\begin{array}{c}\text { K K (68.37\%), Mg K } \\
(4.66 \%), \text { Ca K }(7.09 \%)\end{array}$ & Ceiba pentandra & $9.20: 1$ & 1.978 & 60 & 60 & $98.69 \%$ & [14] \\
\hline CPK & 500 & 4 & $\begin{array}{c}\mathrm{K}(47.67 \%), \mathrm{Ca}(5.56 \%) \\
\mathrm{Mg}(4.21 \%)\end{array}$ & $\begin{array}{l}\text { Neem-rubber-honne } \\
\text { oil blend }\end{array}$ & $12: 1$ & 1.16 & $150 \mathrm{~W}$ & 6 & 98.45 & $\begin{array}{l}\text { Present } \\
\text { study }\end{array}$ \\
\hline
\end{tabular}


Menegehetti et al. [24] evaluated mixtures of cottonseed/castor oils (50:50) and soybean/castor (25:75) oils for biodiesel synthesis and reported 86 and $87 \mathrm{wt} . \%$ yields, respectively. Khalil et al. [25] produced biodiesel from a blend of palm oil/rubber seed oil (50:50) and obtained $97 \mathrm{wt} \% \%$ yield. Also, a mixture of pongamia/neem oils (70:30) was converted to biodiesel with a yield of $86.3 \mathrm{wt} . \%$ [26]. In the study of mixture of waste cooking/honne oils (70:30) carried out with the aid of microwave irradiation, a yield of $97.65 \mathrm{wt} . \%$ was reported by Milano et al. [27]. In the work of Miraculas et al. [28], a mixture of pongamia/jatropha/honne oils (in equal proportions) was used to produce biodiesel with a reported yield of $\sim 98 \mathrm{wt} . \%$. When a mixture of soybean oil and rapeseed oil (50:50) was used as feedstock for biodiesel synthesis by Qiu et al. [29], a yield of $~ 94 \%$ was observed using $\mathrm{KOH}$ of $0.8 \mathrm{wt} . \%$, temperature of $55{ }^{\circ} \mathrm{C}, \mathrm{MeOH}$ :oil blend of 5:1 and time of $2 \mathrm{~h}$. In our previous report on a mixture of rubber seed/neem oils (40:60), $98.77 \mathrm{wt} . \%$ biodiesel yield was achieved under transesterification aided with microwave irradiation [30]. Fadhil et al. [31] obtained $95.2 \pm 2.5 \mathrm{wt}$ \% biodiesel yield when castor seed oil and waste fish oil were mixed together (50:50) using MeOH:blend oil of 8:1, $\mathrm{KOH}$ of $0.5 \mathrm{wt} . \%$, time of $30 \mathrm{~min}$, stirring rate of $600 \mathrm{rpm}$ and temperature of $32{ }^{\circ} \mathrm{C}$. In all of these reports biodiesel was synthesized through transesterification processes with either $\mathrm{KOH}$ or $\mathrm{NaOH}$ as the homogeneous catalyst, except in our work in which calcined ash of elephant ear pod husk was used as a base catalyst. Besides the work of Milano et al. [27] and Falowo et al. [30], none of the other works applied microwave irradiation which accounts for the longer time needed to complete the transesterification reactions.

The focus of this present study was to synthesize a functional heterogeneous base catalyst from a mixture of cocoa (Theobroma cacao) pod husk, plantain (Musa paradisiaca) peel and kola nut (Cola nitida) pod husk (CPK) and apply it to transesterification of a ternary blend of inedible oils made up of honne (Calophyllum inophyllum), neem (Azadirachta indica) and rubber seed (Hevea brasiliensis) using microwave-assisted transesterification. This was with a view to developing a sustainable path for biodiesel production to deal with both food vs. fuel concerns and environmental threats. Detailed characterization of the developed catalyst was carried out to ascertain its catalytic potential. The important process parameters for the transesterification process were optimized to maximize the biodiesel yield from the oil blend.

\section{Results and Discussion}

\subsection{Calcined CPK Characterization}

\subsubsection{EDX Results on CPK}

Table 2 describes the elemental composition of the analyzed samples of calcined CPK prepared at various temperatures. The major metals present are $\mathrm{K}, \mathrm{Ca}$ and $\mathrm{Mg}$ (Figure 1). From the results, variation of calcination temperature affected the element present and amount of each element as previously established [21].

Table 2. Elemental composition of calcined CPK by EDX.

\begin{tabular}{ccccccccccc}
\hline $\begin{array}{c}\text { Temperature } \\
\left({ }^{\circ} \mathbf{C}\right)\end{array}$ & $\mathbf{0}$ & $\mathbf{M g}$ & $\mathbf{S i}$ & $\mathbf{P}$ & $\mathbf{S}$ & $\mathbf{C l}$ & $\mathbf{K}$ & $\mathbf{C a}$ & $\mathbf{F e}$ & $\mathbf{A l}$ \\
\cline { 2 - 11 } & 40.43 & 4.06 & 0.90 & 1.74 & 1.41 & 1.97 & 43.99 & 5.50 & 0.00 & 0.00 \\
300 & 37.21 & 4.21 & 0.56 & 1.65 & 1.26 & 1.88 & 47.67 & 5.56 & 0.00 & 0.00 \\
500 & 41.20 & 3.05 & 0.79 & 1.61 & 0.92 & 1.88 & 47.93 & 3.93 & 0.00 & 0.00 \\
700 & 41.59 & 1.85 & 1.41 & 1.77 & 1.29 & 1.43 & 45.55 & 4.68 & 0.64 & 0.00 \\
900 & 45.30 & 0.81 & 2.82 & 5.20 & 1.17 & 1.03 & 43.90 & 0.00 & 0.00 & 0.75 \\
1100 & & & & & & & & & &
\end{tabular}

Elements such as $\mathrm{K}, \mathrm{Ca}$ and $\mathrm{Mg}$ are good metals for catalyst formation because of their ability to easily donate electron to other molecules. At $500{ }^{\circ} \mathrm{C}$ and $700{ }^{\circ} \mathrm{C}, \mathrm{K}$ had the highest peak of $47.67 \%$ and $47.93 \%$, respectively, among the elements present. Also, $\mathrm{Mg}$ and $\mathrm{Ca}$ are present in higher amounts at 
$500{ }^{\circ} \mathrm{C}$ than at $700{ }^{\circ} \mathrm{C}$. Increasing the calcination temperature beyond $700{ }^{\circ} \mathrm{C}$ led to a slight reduction in $\mathrm{K}$ content, which could possibly be attributed to the vaporization of $\mathrm{KCl}$ [32]. On the basis of this observation, coupled with the conservation of energy by lowering calcination temperature, additional $\mathrm{CPK}$ production was subsequently carried out at $500^{\circ} \mathrm{C}$.

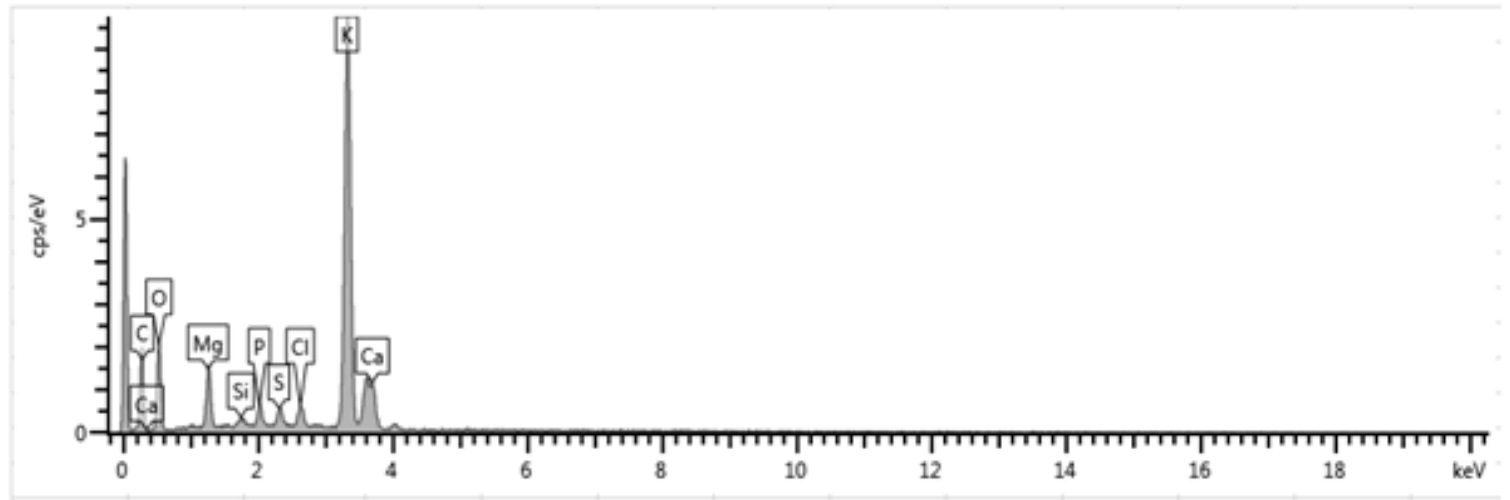

Figure 1. EDX plot of calcined $\mathrm{CPK}$ ash at $500^{\circ} \mathrm{C}$.

The results in this study agree with previous reports. As can be seen in Table 1, $\mathrm{K}$ has been observed to be the dominant element in calcined cocoa pod husk ash [20], calcined plantain peel [22] and calcined kola nut pod ash $[18,19]$. In another report, mass fraction of calcined banana peduncle ash at $700{ }^{\circ} \mathrm{C}$ for $4 \mathrm{~h}$ showed $\mathrm{K}(68.37 \%)$ as the dominant component, but with traces of $\mathrm{Ca}$ and $\mathrm{Mg}$ too [14]. Gohain et al. [15] reported that calcined Carica papaya stem at $700{ }^{\circ} \mathrm{C}$ for $4 \mathrm{~h}$ contains $\mathrm{K}$ (56.71\%), $\mathrm{Ca}(21.08 \%), \mathrm{Na}(14.78 \%)$ and $\mathrm{Mg}(4.41 \%)$. Calcined waste of cupuaçu seeds at $800{ }^{\circ} \mathrm{C}$ for $4 \mathrm{~h}$ was reported to contain $\mathrm{K}, \mathrm{Ca}$ and $\mathrm{Mg}$ with composition of 54.76, 17.57 and 3.61\%, respectively [12]. Also, it was found that $\mathrm{K}(56.13 \%)$ and $\mathrm{Ca}(26.04 \%)$ were the predominant elements in Brassica nigra leaves calcined at $550{ }^{\circ} \mathrm{C}$ for $2 \mathrm{~h}$ [13]. All of these calcined ashes from agricultural wastes have been tested as catalysts for transesterification reactions to synthesize biodiesel with great success.

\subsubsection{SEM Analysis of Calcined CPK}

The morphological nature of the calcined CPK shows small aggregates of fine particles (Figure 2). The material is porous and spongy in nature, with clusters of small particles scattered in the micrographs. It is worth mentioning that the sintering of metal oxide could be responsible for the agglomerated particles at the calcined temperature [30].

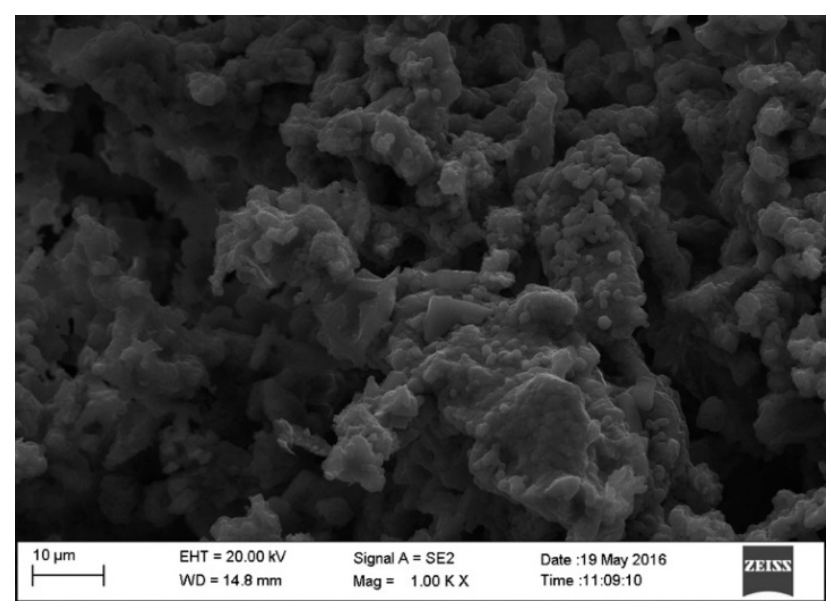

Figure 2. SEM image of calcined $\mathrm{CPK}$ ash at $500{ }^{\circ} \mathrm{C}$. 
The particle structure of this nature usually exhibits a higher surface area, thereby suggesting a good catalytic activity of the developed catalyst. The SEM images reveal irregularly sized particles of uneven shape. Observations of similar structures in ashes developed from cocoa pod husk [21], ripe plantain peel [23], unripe plantain peel [22] and kola nut pod husk [18] have been reported.

\subsubsection{XRD Pattern of Calcined CPK}

The crystalline structure of the calcined CPK was described by the corresponding XRD diffractogram (Figure 3). The diffraction peak centered at $2 \theta$ shows numerous peaks which is an indication of crystalline phases. Calcination led to the decomposition of the compounds present in the $\mathrm{CPK}$ to $\mathrm{KCl}, \mathrm{K}_{2} \mathrm{CO}_{3} \cdot 1.5 \mathrm{H}_{2} \mathrm{O}$ and $\mathrm{K}_{2} \mathrm{Ca}\left(\mathrm{CO}_{3}\right)$. The XRD spectrum shows that potassium compounds dominated the phases. The observation agrees with the elemental composition obtained by the EDX analysis supporting that $\mathrm{K}$ is the predominant element in the CPK. Furthermore, our observation aligns with earlier reports on the calcined individual agrowastes which was combined in this study [18,21-23]. This is also true for agrowastes such as banana peduncle and C. papaya stem $[14,15]$.

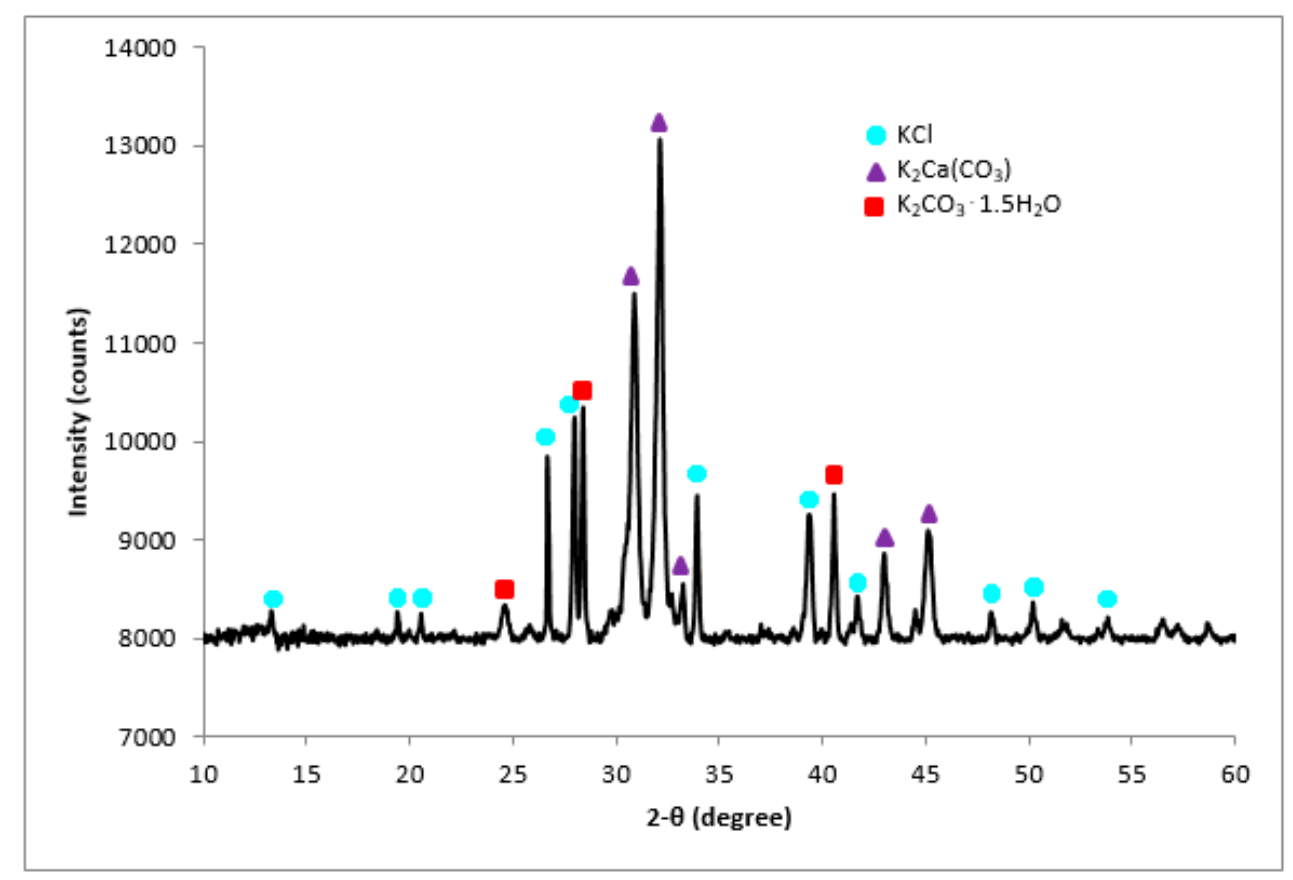

Figure 3. XRD plot of calcined CPK ash at $500{ }^{\circ} \mathrm{C}$.

\subsubsection{IR Spectrum for Calcined CPK}

The IR spectrum of calcined CPK is shown in Figure 4. A close observation shows adsorption bands at 1367 and $879 \mathrm{~cm}^{-1}$ that indicate the presence of carbonate stretching and bending of $\mathrm{C}-\mathrm{O}$ vibrations [33]. Also, the - $\mathrm{C}-\mathrm{O}$ stretching and bending vibrations of carbonate was detected at $1132 \mathrm{~cm}^{-1}$ [13]. The phosphate and silicate ion components are identified by the adsorption band of $1029 \mathrm{~cm}^{-1}[7,13,23]$. The band at $679 \mathrm{~cm}^{-1}$ is attributable to stretching vibrations of K-O [15]. The characteristic bands at 879 and $679 \mathrm{~cm}^{-1}$ indicate the presence of $\mathrm{K}_{2} \mathrm{CO}_{3} \cdot 1.5 \mathrm{H}_{2} \mathrm{O}$. In addition, a characteristic band for $\mathrm{K}_{2} \mathrm{CO}_{3}$ at $1367 \mathrm{~cm}^{-1}$ is prominent in calcined CPK ash [7,32]. This band is also supported by the strong presence of $\mathrm{K}_{2} \mathrm{CO}_{3}$ in the XRD spectrum of calcined CPK (Figure 3). The EDX results (Table 2) corroborate the observed functional groups identified in the IR spectrum of the CPK. Previous studies on the synthesis of solid catalysts from cocoa pod husk [21], plantain peel $[22,23]$ and kola nut pod husk [18], the precursors of the calcined CPK, show that their spectra have similar functional groups to those observed by IR in this study. In addition, these compounds 
have been reported in calcined ashes of Brassica nigra leaves [13], C. papaya stem [15] and elephant ear pod husk [30].

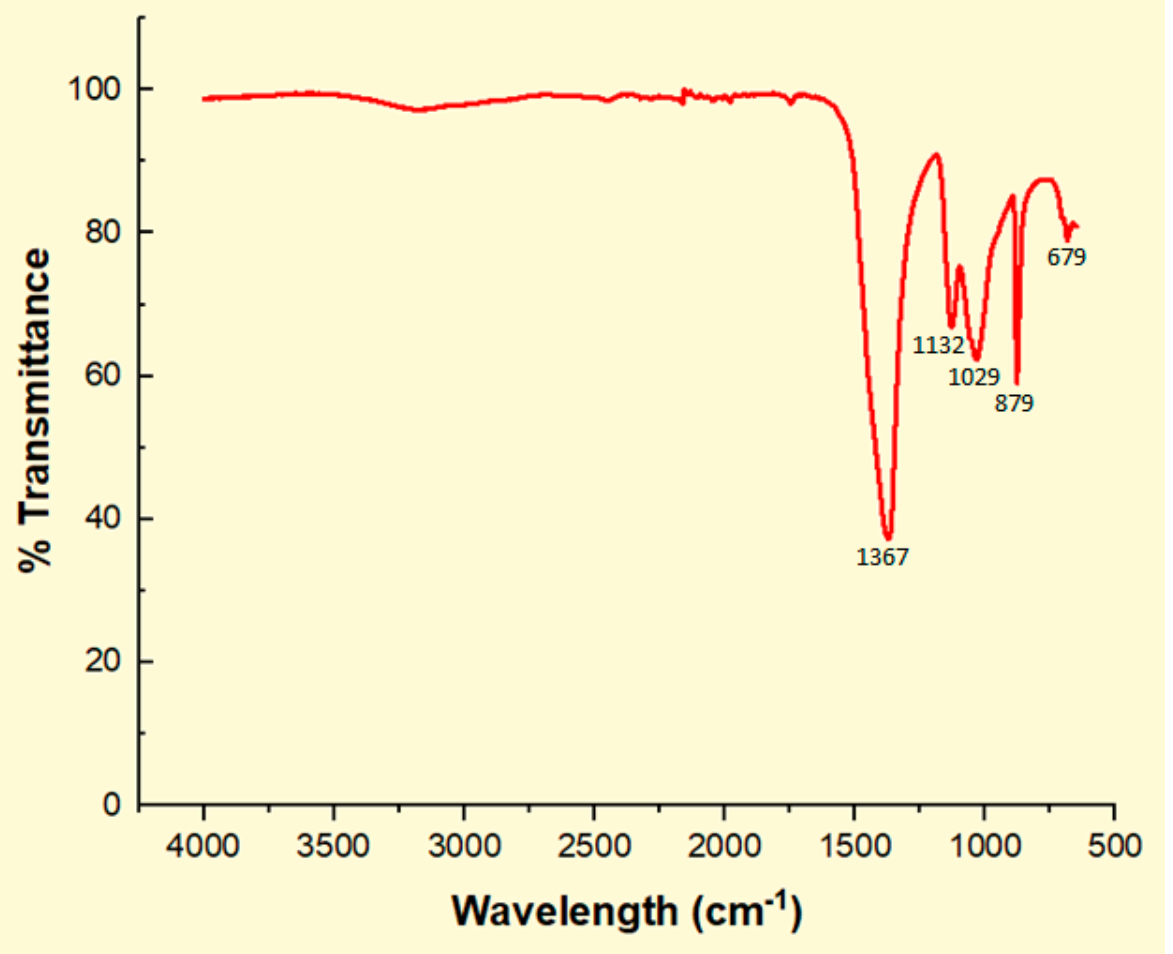

Figure 4. FTIR spectrum of calcined CPK ash at $500{ }^{\circ} \mathrm{C}$.

\subsubsection{Surface Properties of Calcined CPK}

Measurable quantities such as pore volume and specific surface area that described physical properties of the calcined $\mathrm{CPK}$ at $500{ }^{\circ} \mathrm{C}$ were determined by physisorption of nitrogen gas $\left(\mathrm{N}_{2}\right)$ at $77.3 \mathrm{~K}$. The calcined CPK had a BET surface area of $16.871 \mathrm{~m}^{2} / \mathrm{g}$ and the BJH pore volume was $0.041 \mathrm{~cm}^{3} / \mathrm{g}$. The BET surface areas reported for calcined ashes of cocoa pod husk, plantain peel and kola nut pod husk are 2.76, 18.80 and 5.22, respectively [18,21,23]. This shows that combing the agrowastes has improved the surface areas of both calcined ashes of cocoa pod husk and kola nut pod husk. The surface area of the calcined CPK ash in this present study is much higher compare to calcined ashes of Brassica nigra leaves, Musa acuminata peel and wood obtained from Acacia nilotica with $7.038,1.4546$ and $1.33-3.72 \mathrm{~m}^{2} / \mathrm{g}$, respectively $[13,16,32]$. The physisorption isotherms of the calcined CPK ash is depicted in Figure 5. At low $\mathrm{P} / \mathrm{P}_{\mathrm{o}}$, the adsorption isotherm shows progressive increase in the volume of $\mathrm{N}_{2}$ adsorbed, an important feature in type IV isotherm [34,35]. A sharp uptake in adsorbate volume observed at $\mathrm{P} / \mathrm{P}_{\mathrm{o}}>0.9$ can be linked to adsorption in the mesopores region of the catalyst together with type $\mathrm{H} 3$ loop, an indication of the presence of mesopores that consists of agglomerates in the calcined CPK [30,34-36]. The plot of the BJH pore-size distribution for the calcined CPK is illustrated in Figure 6. The plot suggests the presence of nanoparticles of mesopore size $(2-50 \mathrm{~nm})$ for the calcined CPK ash [34]. 


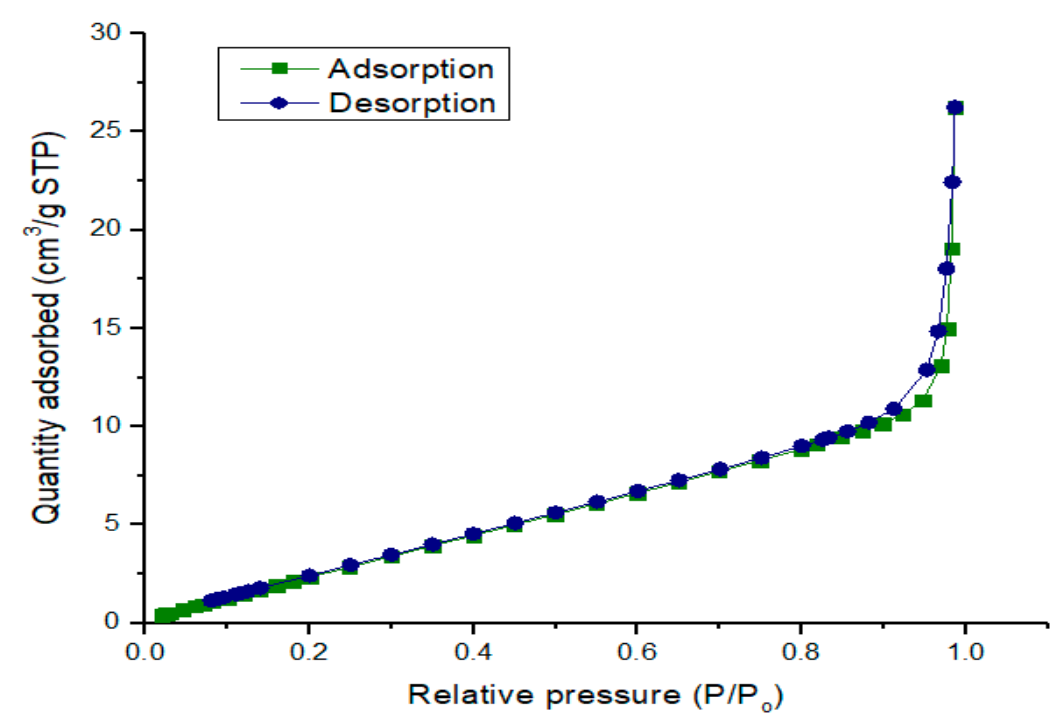

Figure 5. Plot of physisorption isotherms against relative pressure.

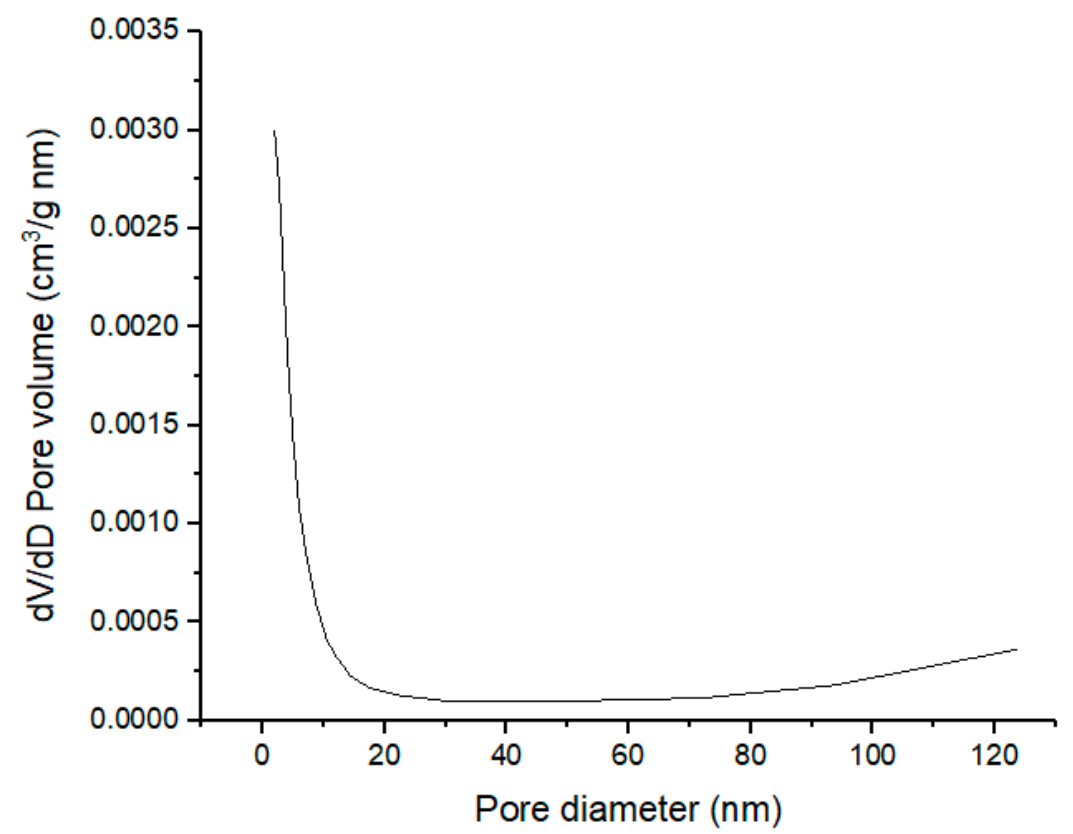

Figure 6. Pore size distribution of calcined $\mathrm{CPK}$ ash at $500{ }^{\circ} \mathrm{C}$.

\subsection{Physicochemical Properties of Oil Blends}

The suitability of the oil blend for biodiesel synthesis was determined by evaluating the physicochemical properties of each oil blend sample obtained from crude honne, rubber seed and neem oils. Based on the properties of the oil blends presented in Table 3, acid value was extremely high for all oil blends with H20R20N60 having the lowest. The value increases with decrease in the proportion of neem oil in the oil blend. Oil density varies based on the nature of the triglycerides [37]. In this study, the density of the oil blend increases with increase in the amount of neem oil but decrease with the increase in rubber seed oil. Changes in kinematic viscosity across the blend follow the same pattern as that of density since both have a linear correlation [38]. Kinematic viscosity was lowest when the honne oil had highest proportion. Iodine value increased as the proportion of rubber seed oil increased in the blends while the value decreased as the proportion of neem oil in the mixture increased. Though, calorific value of all blends was high, particularly when honne and neem oils are high in the mixture, however, there was an appreciable increase in H20R20N60 (code named HRNO). 
Therefore, properties such as lower saponification value, acid value, iodine value and high calorific value made HRNO blend a suitable choice for the biodiesel conversion.

Table 3. Physicochemical properties of hone-rubber seed-neem oil blends.

\begin{tabular}{cccccccc}
\hline Properties & H20R60N20 & H40R40N20 & H60R20N20 & H20R40N40 & H40R20N40 & H20R20N60 & H33R33N33 \\
\hline RI & $1.4726 \pm 0$ & $1.4732 \pm 0$ & $1.4743 \pm 0$ & $1.4738 \pm 0$ & $1.4745 \pm 0.02$ & $1.4732 \pm 0.01$ & $1.4737 \pm 0$ \\
Density $\left(\mathrm{g} / \mathrm{cm}^{3}\right)$ & $0.931 \pm 0.01$ & $0.93 \pm 0.02$ & $0.934 \pm 0.2$ & $0.935 \pm 0.94$ & $0.935 \pm 0.01$ & $0.938 \pm 1.34$ & $0.934 \pm 0.01$ \\
Viscosity $\left(\mathrm{mm}^{2} / \mathrm{s}\right)$ & $51.31 \pm 1.67$ & $49.06 \pm 0.78$ & $47.99 \pm 0.99$ & $65.08 \pm 0.22$ & $57.48 \pm 1.15$ & $66.15 \pm 2.08$ & $59.1 \pm 0.18$ \\
Acid Value $(\mathrm{mg} \mathrm{KOH} / \mathrm{g})^{55.68 \pm 2.2}$ & $47.01 \pm 0.11$ & $41.4 \pm 0.11$ & $42.53 \pm 0.12$ & $35.35 \pm 0.12$ & $31.97 \pm 0.11$ & $39.5 \pm 0.46$ \\
IV $\left(\mathrm{g} \mathrm{I}_{2} / 100 \mathrm{~g} \mathrm{oil}\right)$ & $90.62 \pm 2.4$ & $85.76 \pm 1.46$ & $87.72 \pm 1.46$ & $84.84 \pm 2.46$ & $82.38 \pm 1.94$ & $81.89 \pm 2.42$ & $83.4 \pm 0.99$ \\
SV (mg KOH/g) & $219.49 \pm 0.70$ & $236.32 \pm 0.70$ & $244.04 \pm 0.34$ & $254.55 \pm 0.70$ & $241.94 \pm 0.61$ & $206.17 \pm 1.40$ & $224.4 \pm 0.48$ \\
Calorific value $(\mathrm{MJ} / \mathrm{kg})$ & $39.07 \pm 0.07$ & $38.45 \pm 0.05$ & $38.11 \pm 0.01$ & $37.73 \pm 0.06$ & $38.26 \pm 0.04$ & $39.75 \pm 0.02$ & $39 \pm 0.01$ \\
\hline
\end{tabular}

RI-refractive index, IV_-iodine value, SV-saponification value, value. Values reported are mean with standard deviation of triplicate determinations.

\subsection{Results of Esterification of HRNO}

The pretreatment step, which is an esterification reaction, was included to reduce the acid value of the HRNO to $<2 \mathrm{mg} \mathrm{KOH} / \mathrm{g}$ oil or $\% \mathrm{FFA}<1$, so as to avoid soap formation during the transesterification process. The results obtained showed a significant reduction in \%FFA from 16.07 to a final value of $0.88 \pm 0.085$ using reaction time of $120 \mathrm{~min}$, temperature of $65^{\circ} \mathrm{C}, \mathrm{MeOH}$ : Oil blend of $25: 1$ and catalyst weight of $10 \mathrm{wt} . \%$. The result shows the good catalytic capability of the ferric sulfate in addition to easy separation and recovery of the catalyst [39]. Similar reduction of \%FFA was reported at the same processing condition using a blend of rubber seed oil and neem oil. Hence, the process condition was used for the mass production of esterified HRNO used for the transesterification step.

\subsection{Modelling Results of Transesterification Process}

The central composite rotatable design (CCRD) modeling of the transesterification of HRNO via irradiation with microwave was carried out. The regression model equation obtained is described by the Equation (1):

$$
\begin{gathered}
\text { HRNOB }=+87.89+2.08 A-0.50 B+1.10 C+1.67 A B+3.22 A C-4.57 B C \\
-1.59 A^{2}+0.52 B^{2}+0.63 C^{2}
\end{gathered}
$$

where, HRNOB (wt.\%) is the response from the oil blend, the terms $A, B$ and $C$ represent $\mathrm{MeOH}$ : HRNO, CPK concentration (wt.\%) and reaction time (min), respectively. $A B, A C$, and $B C$ are the interaction terms, and $A^{2}, B^{2}$, and $C^{2}$ are the quadratic terms of the independent variables.

ANOVA results and regression analysis of the selected responses are presented in Table 4 to establish the level of significance of the model as well as all the terms of the model. The $F$-value of 87.33 and $p$ value of 0.0001 indicate the statistical significance of the process of the model. From Table 4, all the model terms are significant, except $\mathrm{CPK}$ loading $(\mathrm{B})$ and the quadratic term of $\mathrm{CPK}$ loading $\left(\mathrm{B}^{2}\right)$. $\mathrm{MeOH}$ : HRNO has the highest significant effect on the honne-rubber seed-neem oil biodiesel (HRNOB) yield out of the three process input variables investigated. This implies that it has stronger effect on the HRNOB yield than both reaction time and CPK loading.

The fitness of experimental data to a model can be explained by its $R^{2} . R^{2}$ of the model was evaluated as 0.9937 , which signifies that the model could explain $99.37 \%$ of the variability [21]. For adequate precision, the required ratio should be $>4$, for the value of 42.38 for the model indicates strong signal for the design purpose. Therefore, the design space can be directed by the model. Coefficient of variation $(\mathrm{CV})$ is used to evaluate the capability of a model; a value $<10 \%$ indicates efficient model. The CV obtained for the model is $0.68 \%$, which suggests that the model is capable of illustrating the process. 
Table 4. Statistical results for the model.

\begin{tabular}{cccccc}
\hline Source of Variance & $\begin{array}{c}\text { Sum of } \\
\text { Squares }\end{array}$ & $\begin{array}{c}\text { Degree of } \\
\text { Freedom }\end{array}$ & $\begin{array}{c}\text { Mean } \\
\text { Square }\end{array}$ & $\boldsymbol{F}$ Value & $p$-Value \\
\hline Model & 282.08 & 9 & 31.34 & 87.33 & $<0.0001$ \\
A-MeOH: HRNO & 17.29 & 1 & 17.29 & 48.17 & 0.0010 \\
B-CPK loading & 0.99 & 1 & 0.99 & 2.77 & 0.1569 \\
C-Time & 4.87 & 1 & 4.87 & 13.56 & 0.0143 \\
AB & 5.60 & 1 & 5.60 & 15.60 & 0.0109 \\
AC & 20.69 & 1 & 20.69 & 57.65 & 0.0006 \\
BC & 41.79 & 1 & 41.79 & 116.44 & 0.0001 \\
A $^{2}$ & 19.51 & 1 & 19.51 & 54.37 & 0.0007 \\
B $^{2}$ & 2.10 & 1 & 2.10 & 5.86 & 0.0601 \\
C $^{2}$ & 3.06 & 1 & 3.06 & 8.52 & 0.0331 \\
Lack of fit & 1.51 & 1 & 1.51 & 20.95 & 0.0102 \\
\hline Fit statistics & & & & & \\
\hline Standard deviation & 0.60 & & & & \\
Mean & 87.65 & & & & \\
Coefficient of variation $(\%)$ & 0.68 & & & & \\
$\mathrm{R}^{2}$ & 0.9937 & & & &
\end{tabular}

Figure 7a displays the plot of predicted HRNOB yields by the model versus the experimental HRNOB yields obtained in the laboratory. The predicted yields by the model are close in values to the experimental yields, which demonstrates the effectiveness of the model. It should be noted that the pure error in this model is insignificant within the range of process parameters investigated due to the near-alignment of experimental HRNOB yields and predicted HRNOB yields; which further confirms a good agreement between the model predicted yields and the experimental yields. Residual is a value between the experimental and predicted value. Hence, randomness of the experimental errors would make the residuals to follow a normal distribution [40]. Figure $7 \mathrm{~b}$ shows a normal distribution of studentized residuals since it is a straight line and not S-shape curve [41]. Figure 7c shows the plot of studentized residuals against model predicted HRNOB yields. The data points randomly scattered within the boundary, which may mean that the variation is consistent for all values of the response, an indication that the model is appropriate. The plot of outlier $t$ for all experimental runs can be visualized as shown in Figure $7 \mathrm{~d}$. All the studentized residuals are within the \pm 3.0 interval limit, demonstrating the fitness of the model. The diagnostic plots obtained from this current study are similar to the ones reported for the modeling of transesterification process of neem-rubber seed oil blend with methanol over calcined elephant ear pod husk as catalyst [30]. Also, similar plots are reported for the model developed for the transesterification of soybean oil with ethanol using calcined waste cupuaçu seed as a solid catalyst [12]. 


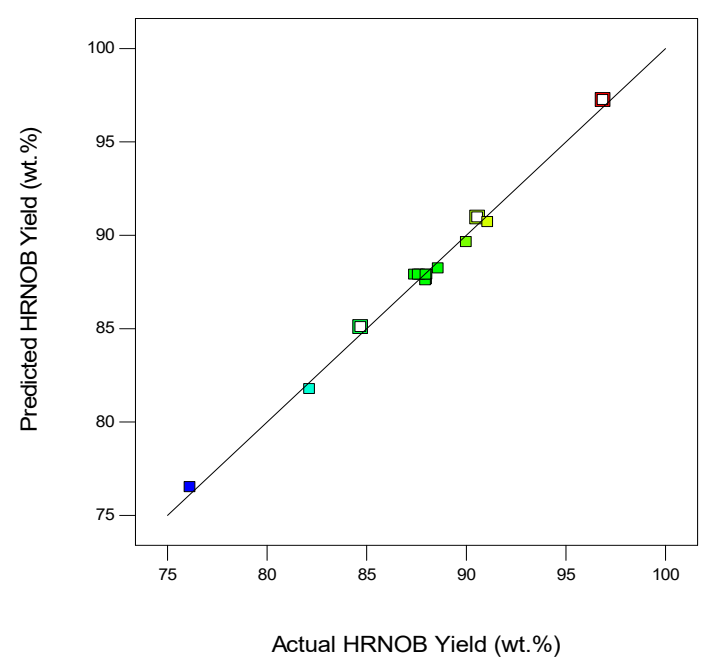

(a)

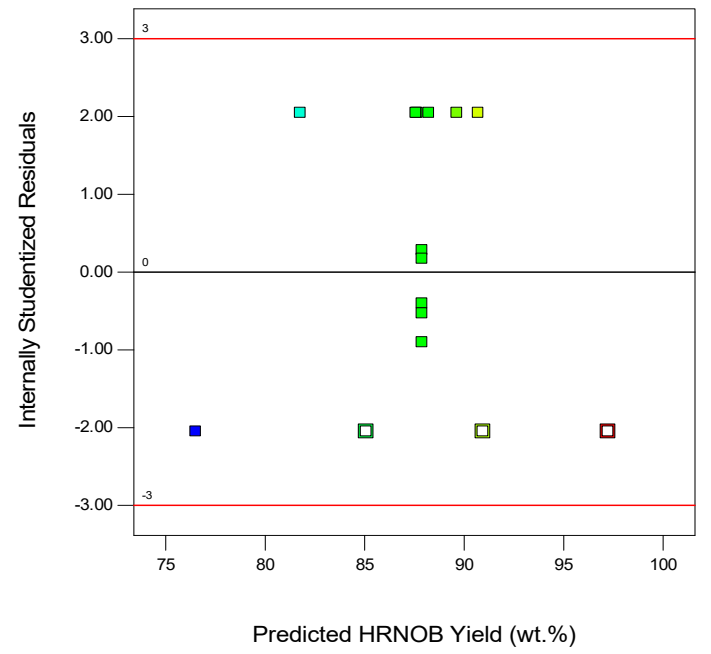

(c)

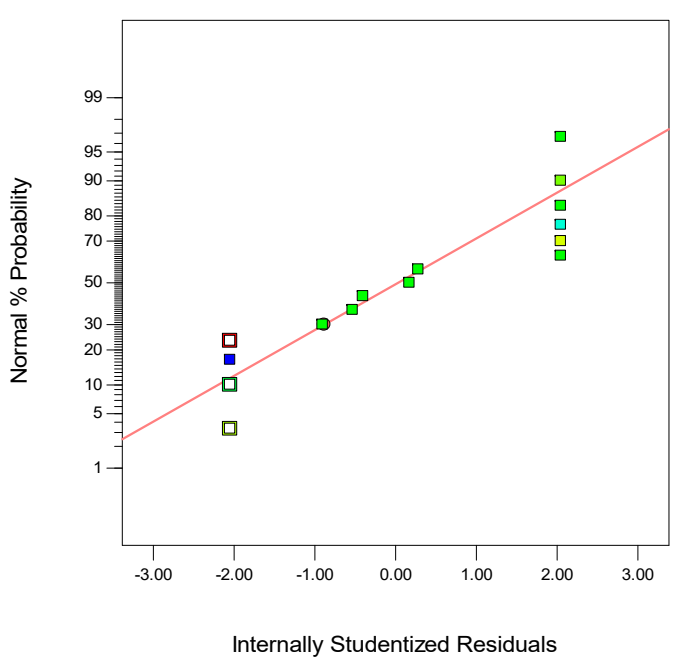

(b)

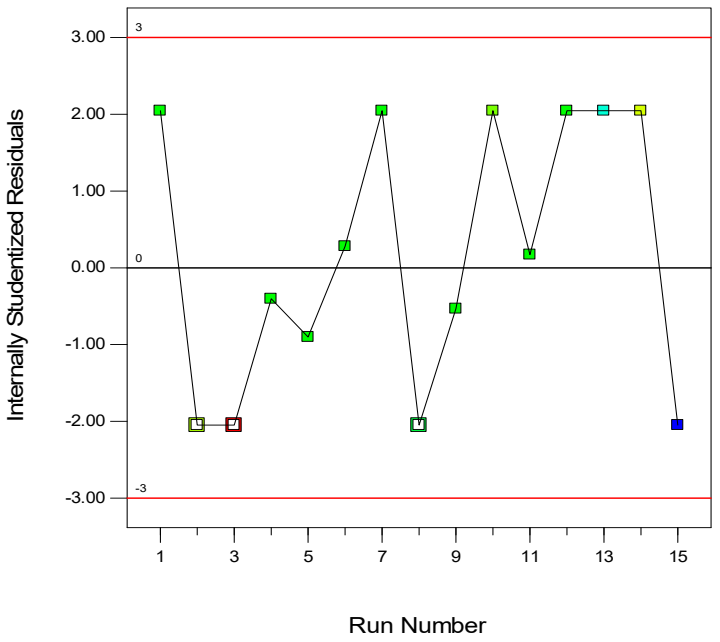

(d)

Figure 7. Diagnostic plots of the surface model for HRNOB synthesis.

\subsection{Interactive Effect of Process Parameters on HRNOB}

Two-dimensional (contour) interactive effect of CPK loading and MeOH: HRNO while time was held constant is shown in Figure 8a. This plot reveals that at low CPK concentration, HRNOB yield increases with an increase in MeOH:HRNO. Also, at high levels of both parameters, the plot reveals a direct relationship between CPK concentration and $\mathrm{MeOH}$ :HRNO which leads to high HRNOB yield. It has been shown that as the amount of catalyst increases, transesterification reaction accelerates due to attainment of equilibrium in shorter time [42]. Visual inspection of this plot could explain the reason the CPK loading is insignificant in the ANOVA results.

The two-dimensional plot of reaction time and CPK loading at constant MeOH: HRNO of 9:1 is shown in Figure 8b. From the plot, an increase in CPK loading does not significantly increase the HRNOB yield with time. While the HRNOB yield is maximum at the highest reaction time and lowest CPK amount, any further increase in CPK concentration at that point leads to sharp reduction in biodiesel yield, though the HRNOB yield at high catalyst loading later increases with a reduction in reaction time. The level of significance of reaction time could be attributed to the effectiveness of microwave irradiation in enhancing the conversion rate of the reactant mixture. Compared to conventional heating method, microwave irradiation within short time proved to be efficient in producing biodiesel. For instance, Nayak and Vyas [43] obtained biodiesel of 99.3\% from papaya oil within $3.3 \mathrm{~min}$ when microwave was applied to the transesterification process. Similarly, biodiesel yield of $95.42 \%$ was observed within $388 \mathrm{~s}$ 
when transesterification of Ceiba pentandra oil was used under microwave-assisted transesterification [44]. In our study of rubber-neem oil blend, biodiesel yield of $98.77 \pm 0.16 \mathrm{wt} . \%$ was observed through transesterification-aided with microwave within $5.88 \mathrm{~min}$ [30].

Figure $8 \mathrm{c}$ shows the interaction between time and MeOH: HRNO on HRNOB yield at constant $\mathrm{CPK}$ loading of $3 \mathrm{wt} . \%$. In microwave-aided transesterification, reaction time has been shown to have significant effect on biodiesel yield [30,45]. At low reaction time and low $\mathrm{MeOH}$ : $\mathrm{HRNO}$, the biodiesel yield barely increased. This shows that enough time and high $\mathrm{MeOH}$ : HRNO are requirements for high biodiesel formation [7]. Thus, interaction of these two variables at the highest points increased the HRNOB yield. Both time and $\mathrm{MeOH}$ have been demonstrated to influence biodiesel formation. $\mathrm{MeOH}$ level higher than what is required in terms of stochiometric is needed to drive the equilibrium reaction forward and at the same time, enough time is needed for the reaction to be completed. These observations have been reported in previous studies on transesterification reactions $[12,30,43]$.

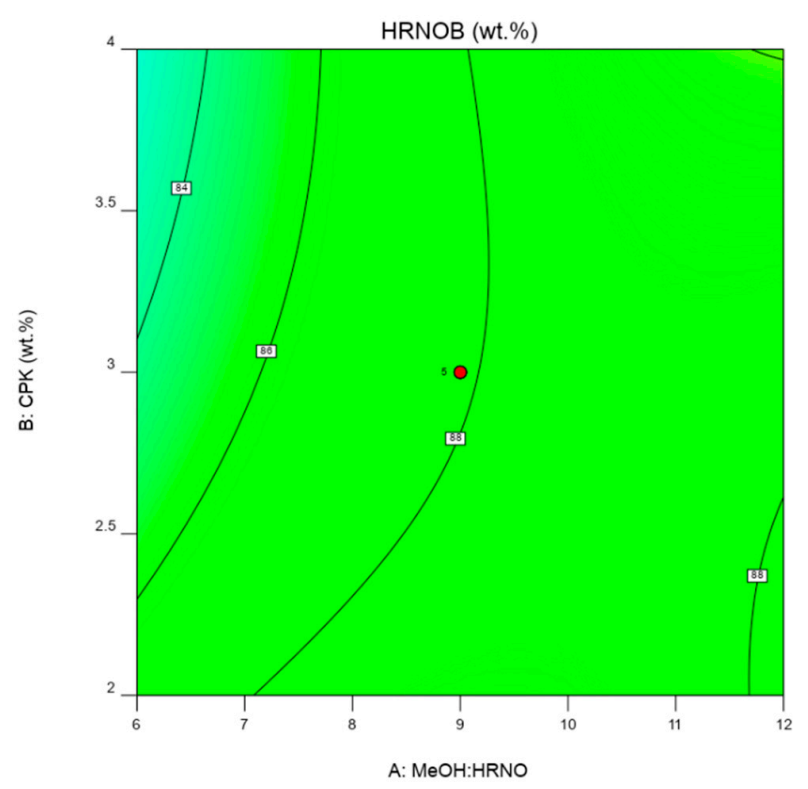

(a)

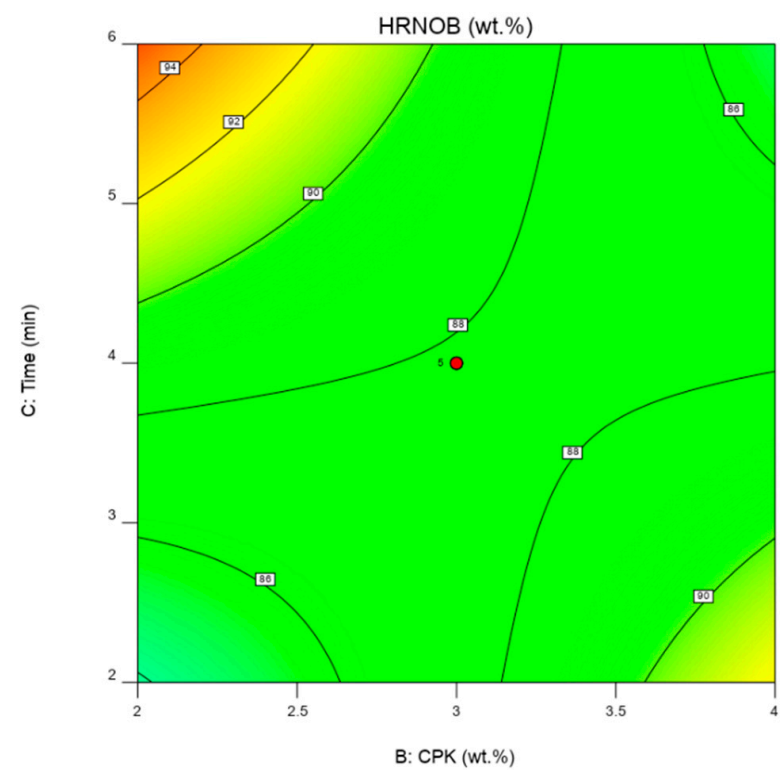

(b)

Figure 8. Cont. 


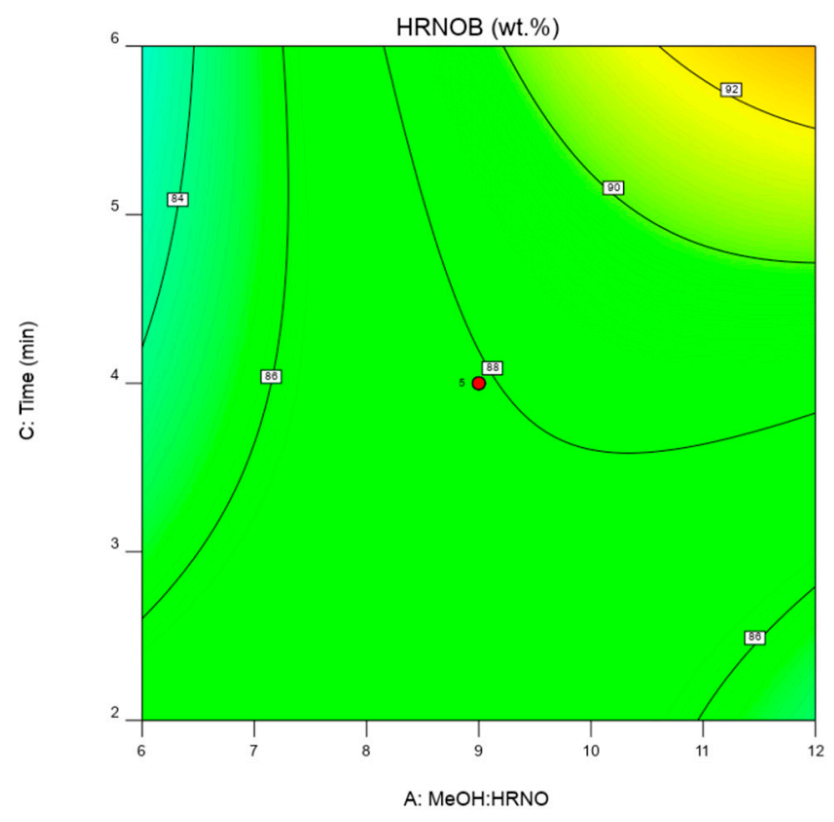

(c)

Figure 8. (a)-Two-dimensional plot of CPK loading and MeOH:HRNO on HRNOB yield. (b) - Two-dimensional plot of CPK loading and time on HRNOB yield. (c)-Two-dimensional plot of time and MeOH: HRNO on HRNOB yield.

\subsection{Optimization Condition and Model Validation}

The optimum values suggested for the three process input variables investigated in this study after solving the regression equation (Equation (1)) are MeOH:HRNO of 12:1, CPK of 1.158 wt.\% and reaction time of 6 min with HRNOB yield predicted as $99 \mathrm{wt} . \%$ at desirability of 1.0. The optimal condition predicted was proved by validation experiment repeated three times. An average of $98.45 \mathrm{wt} . \%$ HRNOB yield was observed, indicating that the model could accurately predict biodiesel yield. In a study of biodiesel synthesis using papaya oil and microwave-assisted transesterification, optimum biodiesel yield of $99.93 \mathrm{wt} . \%$ was obtained at $\mathrm{NaOH}$ loading of $0.95 \mathrm{wt} . \%$, temperature of $62.33^{\circ} \mathrm{C}$, reaction time of $3.3 \mathrm{~min}$ and $\mathrm{MeOH}$ :oil ratio of 9.5:1 [43]. In another study involving blend of waste cooking oil and honne oil, it was shown that maximum biodiesel yield of $97.40 \mathrm{wt} . \%$ can be produced via microwave-aided transesterification using a $\mathrm{KOH}$ concentration of $0.774 \mathrm{wt} . \%$, stirring speed of $600 \mathrm{rpm}, \mathrm{MeOH}$ :oil of $59.60 \mathrm{vol} . \%$, time of $7.15 \mathrm{~min}$ and at $100{ }^{\circ} \mathrm{C}$ [27]. Transesterification assisted with microwave was used to convert Ceiba pentandra oil to biodiesel with a maximum yield of $96.19 \%$. using $\mathrm{KOH}$ concentration of $0.84 \%$, stirring speed of $800 \mathrm{rpm}, \mathrm{MeOH}$ :oil of $60 \%$ and reaction time of $388 \mathrm{~s}$ [44]. In our previous study in which rubber seed and neem oils were blended and calcined ash of elephant ear pod husk was applied as a base catalyst, $98.77 \mathrm{wt} . \%$ biodiesel yield was achieved using optimal condition reaction time of $5.88 \mathrm{~min}$, catalyst amount of $2.96 \mathrm{wt} . \%$ and $\mathrm{MeOH}$ : Oil blend of 11.44:1 conducted under microwave irradiation [30]. The results of the current study showed that the CPK developed is effective and compared well with synthetic chemicals $(\mathrm{KOH}$ and $\mathrm{NaOH})$ used as catalysts in other studies (Table 5). 
Table 5. Review of mixed oils transesterification reaction conditions and yields.

\begin{tabular}{|c|c|c|c|c|c|c|}
\hline Mixed Oils & Nature of Oils & Ratio & Catalyst & Transesterification Condition & Yield & Ref \\
\hline Cottonseed/castor & Both non-edible & $50: 50$ & $\mathrm{NaOH}$ & $\mathrm{MeOH} /$ oil/catalyst of $34: 6: 1$ & $86 \%$ & [24] \\
\hline Soybean/castor & Edible/non-edible & $25: 75$ & $\mathrm{NaOH}$ & $\mathrm{MeOH} /$ oil/catalyst of $34: 6: 1$ & $87 \%$ & [24] \\
\hline Palm oil/rubber seed & Edible/non-edible & $50: 50$ & $\mathrm{KOH}$ & $64^{\circ} \mathrm{C}, 1 \mathrm{~h}$, catalyst of $1.3, \mathrm{MeOH}$ : Oil $6: 1$ & $97 \%$ & [25] \\
\hline Pongamia/neem & Both non-edible & $70: 30$ & $\mathrm{NaOH}$ & $\begin{array}{c}60-65^{\circ} \mathrm{C} \text {, catalyst of } 0.67 \%, \mathrm{MeOH}: \text { Oil } \\
\text { of } 6: 1 \text { and } 77 \mathrm{~min}\end{array}$ & $86.2 \%$ & [26] \\
\hline Waste cooking/honne & Waste/non-edible & $70: 30$ & $\mathrm{KOH}$ & $\begin{array}{c}100{ }^{\circ} \mathrm{C} \text {, catalyst of } 0.774 \mathrm{wt} . \%, 600 \mathrm{rpm} \text {, } \\
\mathrm{MeOH} \text { : Oil of } 59.60 \text { vol. } \% \text { and } 7.15 \mathrm{~min} \\
\text { under microwave irradiation }\end{array}$ & $97.65 \%$ & [27] \\
\hline Pongamia/jatropha/honne & All are non-edible & 1:1:1 & $\mathrm{KOH}$ & $\begin{array}{c}64^{\circ} \mathrm{C} \text {, catalyst of } 1.17 w / v \text {, oil:MeOH of } \\
2.5 v / v \text { and } 95 \mathrm{~min}\end{array}$ & $98 \%$ & [28] \\
\hline Soybean/rapeseed & Both edible & $50: 50$ & $\mathrm{NaOH}$ & $\begin{array}{c}55^{\circ} \mathrm{C} \text {, catalyst of } 0.8 \text { wt. } \%, \mathrm{MeOH} \text { : Oil of } \\
5: 1 \text { and } 2 \mathrm{~h}\end{array}$ & $94 \%$ & [29] \\
\hline Rubber seed/neem & Both non-edible & $40: 60$ & $\begin{array}{l}\text { Calcined ash of } \\
\text { elephant ear pod husk }\end{array}$ & $\begin{array}{c}150 \mathrm{~W}, \mathrm{MeOH} \text { : Oil 11.44:1, catalyst of } \\
2.96 \mathrm{wt} . \% \text { and } 5.88 \mathrm{~min} \text { under } \\
\text { microwave irradiation }\end{array}$ & $98.77 \%$ & {$[30]$} \\
\hline Castor/waste fish oil & Non-edible/waste & $50: 50$ & $\mathrm{KOH}$ & $\begin{array}{c}32{ }^{\circ} \mathrm{C} \text {, catalyst of } 0.5 \mathrm{wt} . \%, \mathrm{MeOH}: \text { Oil of } \\
8: 1,600 \mathrm{rpm} \text { and } 30 \mathrm{~min}\end{array}$ & $95.2 \pm 2.5 \%$ & [31] \\
\hline $\begin{array}{l}\text { Honne/rubber } \\
\text { seed/neem }\end{array}$ & All are non-edible & 1:1:1 & Calcined CPK & $\begin{array}{c}150 \mathrm{~W}, \mathrm{MeOH} \text { : Oil 12:1, catalyst of } 1.158 \\
\text { wt.\% and } 6 \text { min under microwave } \\
\text { irradiation }\end{array}$ & 98.45 wt. $\%$ & Present study \\
\hline
\end{tabular}

Except where indicated as $v / v, \mathrm{MeOH}$ : Oil is in molar ratio. 
The application of microwave irradiation in this present study helped reduced the reaction time significantly compared to the conventional heating via water bath or hotplate used for transesterification reaction. The typical reaction time reported in the conventional transesterification of some oils to biodiesel ranged between $25 \mathrm{~min}$ and $180 \mathrm{~min}[7,13,14,18,20,21]$. Microwave irradiation enhances transesterification reactions through a thermal effect and by evaporation of methanol [46]. The microwave interaction with the triglycerides and methanol results in a large reduction of activation energy due to increased interaction of triglycerides and methanol with the microwave irradiation which results in significant reduction of activation energy because of increased dipolar polarization. The choice of methanol over ethanol for the transesterification process in this current study is also helpful in the reduction of the reaction time used since methanol is a strong microwave absorber [46].

\subsection{Quality of HRNOB}

The characteristics of the HRNO and HRNOB were determined and compared with US and European standards (Table 6). The acid value of the HRNOB was within allowable limit, which means it can be used without causing corrosion in the internal combustion engine and other metal parts [47]. Flash point is the temperature at which biodiesel will ignite when exposed to flame [48]. Biodiesel produced in this study was well within the range specified. High flash point obtained may be due to the predominant presence of C18:1 and C18: 2 in the vegetable oil blend [49]. The cloud point of $+12{ }^{\circ} \mathrm{C}$ and pour point of $-6^{\circ} \mathrm{C}$ of biodiesel produced in this study suggest that this fuel could be used successfully in cold weather areas.

Table 6. Properties of HRNO, HRNOB and standards.

\begin{tabular}{cccccc}
\hline \multirow{2}{*}{ Properties } & \multirow{2}{*}{ Unit } & HRNO & \multirow{2}{*}{ HRNOB } & \multicolumn{2}{c}{ Limit } \\
\cline { 5 - 6 } & & & & EN 14214 & ASTM D6751 \\
\hline Density $\left(15^{\circ} \mathrm{C}\right)$ & $\mathrm{kg} / \mathrm{m}^{3}$ & 938 & 889 & $860-900$ & 880 \\
Acid value & $\mathrm{mg} \mathrm{KOH} / \mathrm{g}$ & 31.97 & 0.45 & $0.5 \mathrm{max}$ & $0.5 \mathrm{max}$ \\
FFA content & $\%$ & 16.07 & 0.226 & $\mathrm{NS}$ & $\mathrm{NS}$ \\
Kinematic viscosity & $\mathrm{mm}^{2} / \mathrm{s}$ & 66.15 & 4.89 & $3.5-5$ & $1.9-6$ \\
Iodine value & $\mathrm{g} \mathrm{I} / 100 \mathrm{~g}$ oil & 81.89 & 44.9 & $<120$ & $\mathrm{NS}$ \\
SV & $\mathrm{mg} \mathrm{KOH} / \mathrm{g}$ & 206.17 & 190.74 & $\mathrm{NS}$ & $\mathrm{NS}$ \\
Cetane number & & 51.34 & 64.8 & $51 \mathrm{~min}$ & $47 \mathrm{~min}$ \\
Calorific Value & $\mathrm{MJ} / \mathrm{kg}$ & 39.75 & 40.94 & 35 & $\mathrm{NS}$ \\
Pour Point & ${ }^{\circ} \mathrm{C}$ & $\mathrm{ND}$ & -6 & $\mathrm{NS}$ & -15 to 16 \\
Flash point & ${ }^{\circ} \mathrm{C}$ & $\mathrm{ND}$ & 128 & $<120$ & 100 to 170 \\
Cloud point & ${ }^{\circ} \mathrm{C}$ & $\mathrm{ND}$ & 12 & $\mathrm{NS}$ & -3 to 12 \\
\hline
\end{tabular}

NS = Not Specified, ND = Not Determined, SV = Saponification value.

All parameters of the HRNOB were found to be within the prescribed standards. Thus, no modifications may be required in using this fuel in an existing diesel engine. The IR spectra of HRNO and HRNOB are depicted in Figure 9a,b. Both spectra have similar peaks and the characteristics of the peaks are described in Table 7. 
(a)

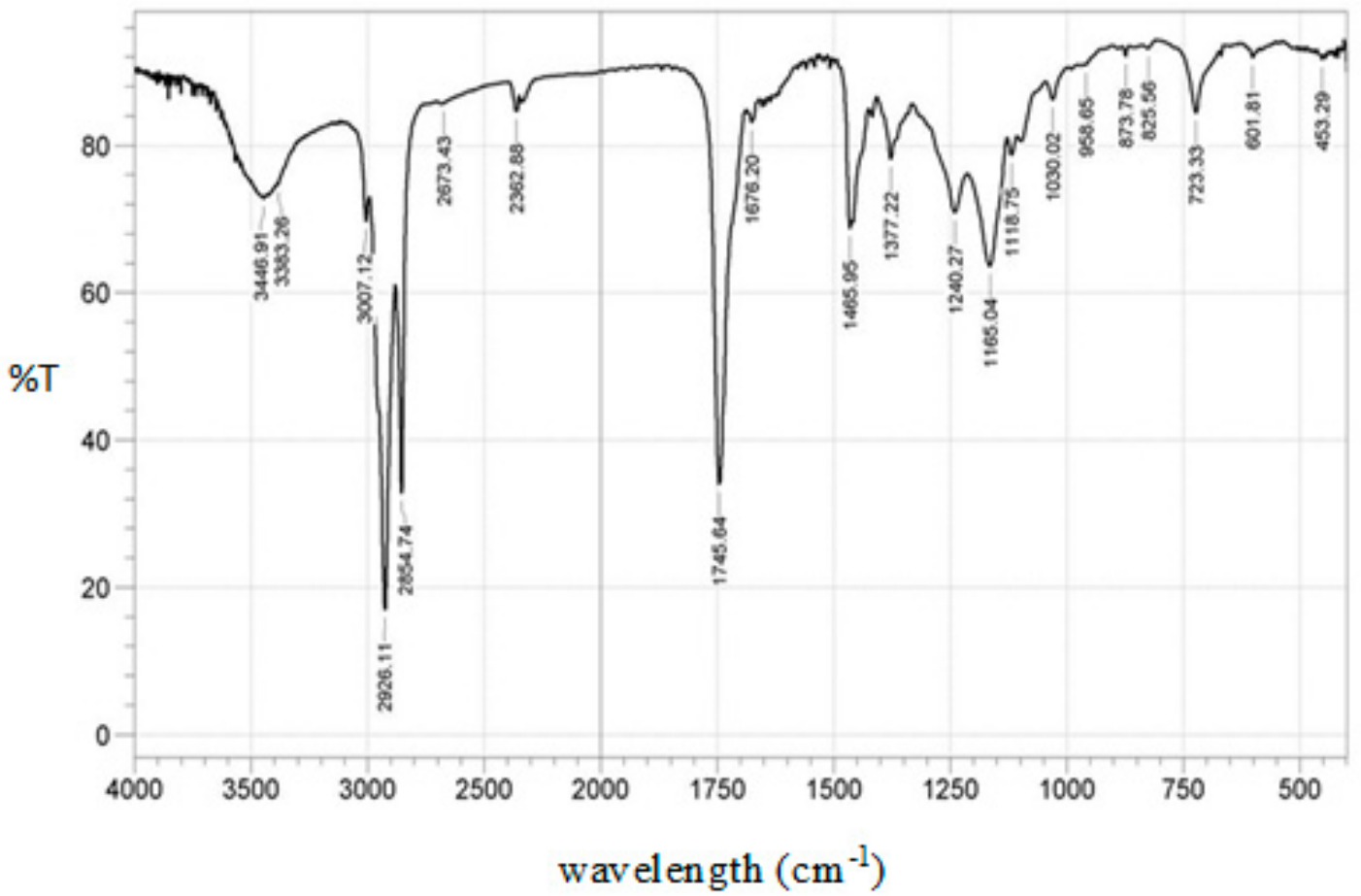

(b)

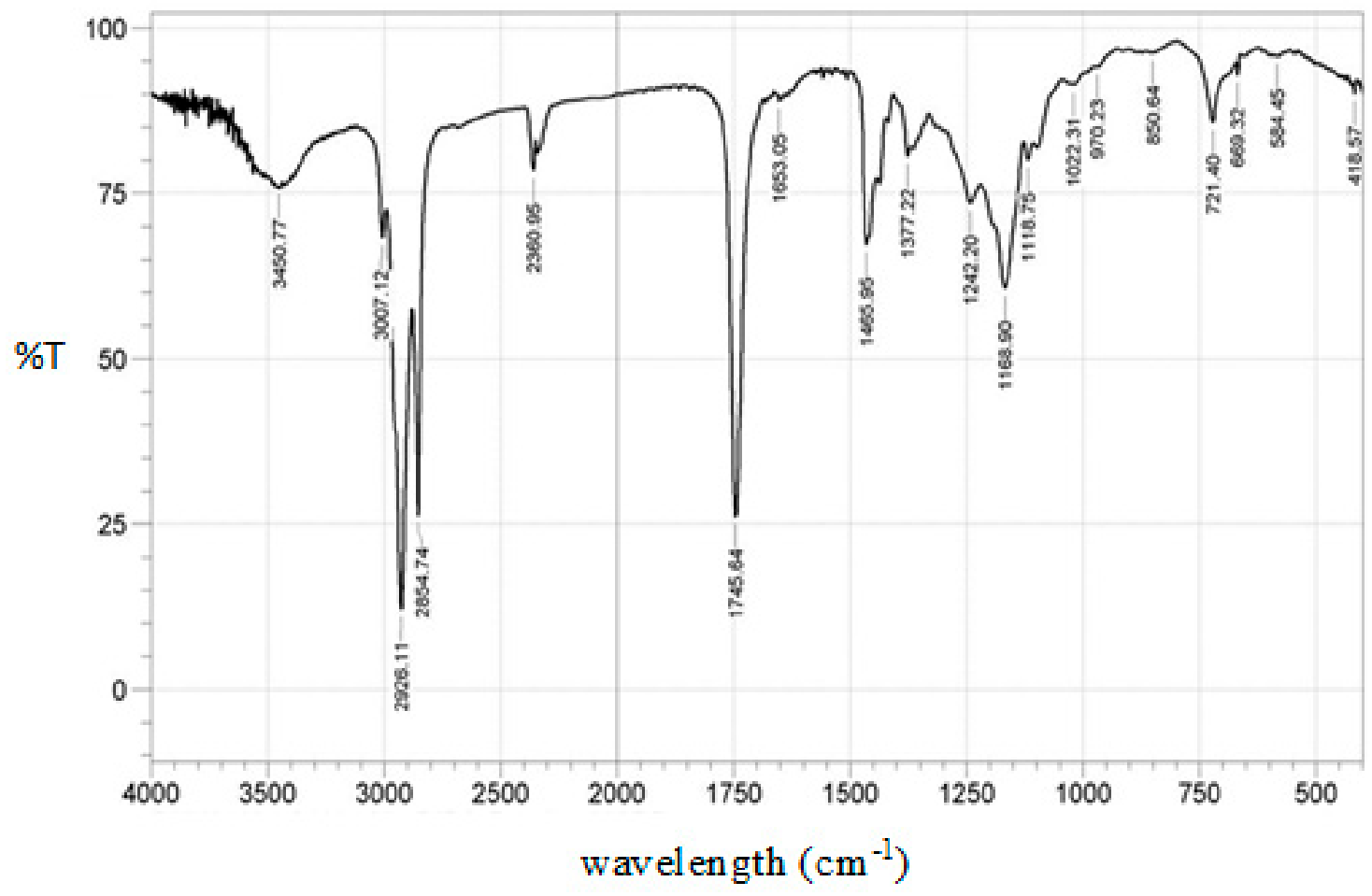

Figure 9. IR spectra; (a) HRNO and (b) HRNOB. 
Table 7. Properties of absorption peaks for HRNO and HRNOB.

\begin{tabular}{|c|c|c|c|c|}
\hline $\begin{array}{l}\text { Wavenumber } \\
\quad\left(\mathrm{cm}^{-1}\right)\end{array}$ & Functional Group & Mode of Vibration & Intensity & Reference \\
\hline 3450 & $-\mathrm{C}=\mathrm{O}$ & Overtone & Weak & {$[18,50,51]$} \\
\hline 3007 & $=\mathrm{C}-\mathrm{H}$ & Stretching & Strong & {$[29,30,52]$} \\
\hline 2926 & $-\mathrm{C}-\mathrm{H}\left(\mathrm{CH}_{2}\right)$ & Asymmetric stretching vibration & Very strong & {$[14,18,50]$} \\
\hline 2854 & $-\mathrm{C}-\mathrm{H}\left(\mathrm{CH}_{2}\right)$ & Symmetric stretching vibration & Very strong & {$[14,18,29]$} \\
\hline 1745 & $-\mathrm{C}=\mathrm{O}$ & Stretching & Very strong & {$[14,18,51]$} \\
\hline 1465 & $-\mathrm{CH}_{2}$ & Shear-type vibration & Medium & {$[30,51,52]$} \\
\hline 1377 & $-\mathrm{CH}_{3}$ & $\begin{array}{l}\text { Bending vibration, symmetric } \\
\text { deformation }\end{array}$ & Medium & {$[30,51,52]$} \\
\hline 1242 & $-\mathrm{CH}_{2}$ & Stretching & Medium & {$[30,52]$} \\
\hline 1168 & $\mathrm{C}-\mathrm{O}-\mathrm{C}$ & Symmetric stretching vibration & strong & {$[14,18,29]$} \\
\hline 721 & $-\mathrm{CH}_{2}$ & $\begin{array}{l}\text { Bending out of plane, rocking } \\
\text { vibration }\end{array}$ & Medium & {$[14,18,29]$} \\
\hline
\end{tabular}

The band around $3446 \mathrm{~cm}^{-1}$ is allocated to $-\mathrm{C}=\mathrm{O}$ overtones. The region from $3009-2854 \mathrm{~cm}^{-1}$ indicates symmetric and asymetric streching vibration of the methyl group $\left(-\mathrm{CH}_{3}\right)$ [53]. The vibration at $2928 \mathrm{~cm}^{-1}$ is assigned to asymmetric $\mathrm{CH}_{3}$ stretching. The well-known carbonyl peak $1750-1700 \mathrm{~cm}^{-1}$ has strong intensity in both spectral. Since no changes are obvious between $1650 \mathrm{~cm}^{-1}$ and $1540 \mathrm{~cm}^{-1}$, it shows no soap was present in the HRNOB $[18,54]$. The fingerprint region $\left(1300-900 \mathrm{~cm}^{-1}\right)$ which is recognized in oils are very distinct in both the spectral for HRNO and HRNOB [18,54]. The rocking vibration is located in the region of $881-723 \mathrm{~cm}^{-1}$. The presence of esters in both the HRNO and HRNOB are charaterized by the strong absorption of $C=O$ streching frequency at $1743 \mathrm{~cm}^{-1}$ and by the strong absorption involving the streching of C-O near $1240 \mathrm{~cm}^{-1}[14,18,51,54]$.

Figure 10 shows the chromatogram of the HRNOB. The fatty acids of the HRNOB contain of a total saturated methyl esters amount of $36.69 \%$, which suggests improved oxidation stability and a total unsaturated methyl esters level of $63.51 \%$, an indication that the biodiesel produced possessed excellent cold flow properties [55]. According to Table 8, the monounsaturated fatty acid of oleic acid is the predominant contributor to the total unsaturated fatty acid methyl esters. The fatty acid composition of HRNOB is quite similar to the findings of previous studies in which biodiesel was produced from neem oil and neem-rubber oil blend [21,30].

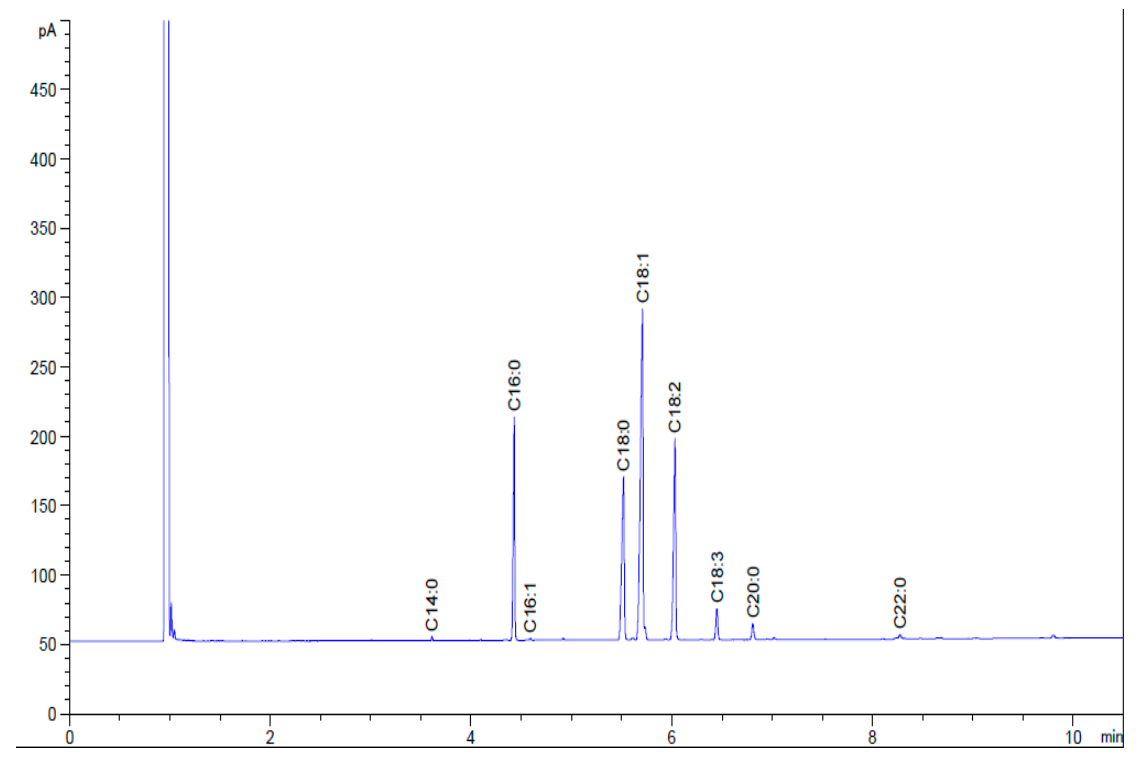

Figure 10. Chromatogram of HRNOB. 
Table 8. Fatty acid profile of HRNOB.

\begin{tabular}{ccccc}
\hline \multirow{2}{*}{$\begin{array}{c}\text { Chain } \\
\text { Length }\end{array}$} & \multicolumn{4}{c}{ Composition (\%) } \\
\cline { 2 - 5 } & HRNOB & Honne & Rubber & Neem \\
\cline { 2 - 5 } & This Study & Ong et al. [47] & Gimbun et al. [56] & Betiku et al. [57] \\
\hline C14:0 & 0.22 & 0.1 & - & - \\
C16:0 & 15.73 & 14.2 & 10.29 & 13.98 \\
C16:1 & 0.12 & 0.3 & - & 0.39 \\
C18:0 & 18.65 & 15.9 & 8.68 & 6.25 \\
C18:1 & 40.42 & 39.8 & 20.07 & 45.00 \\
C18:2 & 20.15 & 28.1 & 58.2 & 32.46 \\
C18:3 & 2.84 & 0.2 & 0.8 & 0.6 \\
C20:0 & 1.55 & 0.8 & - & 0.8 \\
C22:0 & 0.54 & - & - & 0.5 \\
\hline
\end{tabular}

\subsection{Reusability Study of CPK Catalyst}

Reusability study of the calcined CPK was conducted at the optimized process condition and the results observed shown in Figure 11. On completion of each transesterification cycle, the product mixture and the catalyst were separated by centrifugation ( $8000 \mathrm{rpm}$ for $10 \mathrm{~min}$ ). The catalyst was reused without further treatment (no washing FF with acetone or calcination). At the end of the 4th cycle, calcined CPK was able to facilitate 89.46 wt.\% biodiesel yield; hence, the calcined CPK demonstrated appreciable catalytic activity in its reutilization for transesterification. The reduction in the HRNOB yield after each cycle could be attributed to blockage of the catalyst active site and loss of part of the catalyst as well as leaching of active metals from the catalyst.

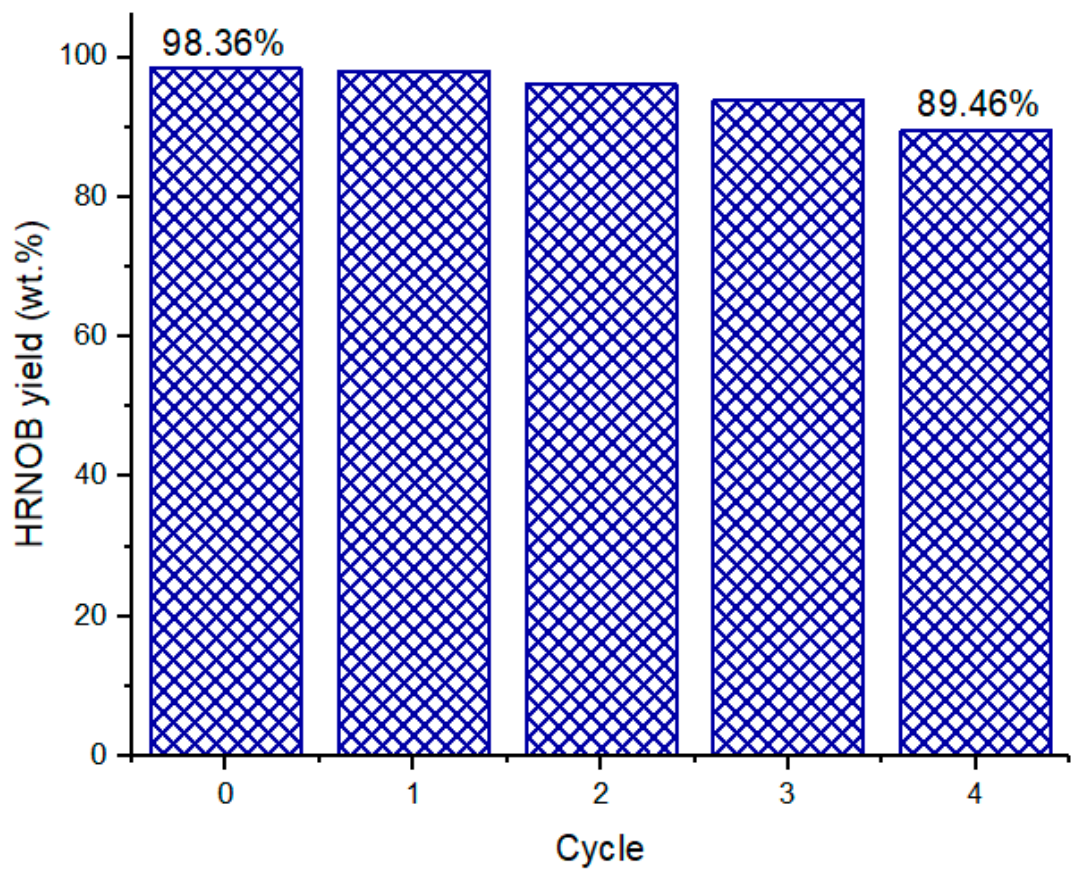

Figure 11. Reusability of calcined CPK at optimized condition.

When Brassica nigra leaves calcined at $550{ }^{\circ} \mathrm{C}$ for $2 \mathrm{~h}$ was reused in the transesterification of soybean oil with methanol, the biodiesel yield reduced from $98.79 \%$ to $96 \%$ after the 3rd cycle [13]. The was a reduction of biodiesel yield from $95.23 \%$ to $85.4 \%$ after 6 th cycle of reuse of catalyst developed by calcination of $C$. papaya stem at $700{ }^{\circ} \mathrm{C}$ for $4 \mathrm{~h}$ [15]. In the case of calcined waste of cupuaçu seeds at $800{ }^{\circ} \mathrm{C}$ for $4 \mathrm{~h}$, its reusability test showed that after the $3 \mathrm{rd}$ cycle, the biodiesel yield from soybean oil was reduced from $98 \%$ to $22 \%$ [12]. We have previously reported that elephant ear pod husk calcined 
at 700 for $4 \mathrm{~h}$ can reused up to four times for transesterification of neem-rubber seed oil blend with a biodiesel yield reduction from $98.68 \%$ to $74.68 \%$ [30]. The reusability potential of the calcined CPK catalyst synthesized compared favourably with those cited in this work.

\section{Experimental}

\subsection{Materials}

Honne oil used for this study was extracted in the Biochemical Engineering Laboratory, Obafemi Awolowo University (Ile-Ife, Nigeria). Rubber seed oil was procured from the Nigerian Rubber Research Institute (Edo State, Nigeria). Neem oil was purchased from the Nigerian National Research Institute for Chemical Technology (Kaduna State, Nigeria). Analytical grade reagents and chemicals were used in this study.

\subsection{Preparation of CPK Catalyst}

CPK catalyst was developed from agrowastes, namely husk of cocoa pods, plantain peel and husk of kola nut pods. The plantain peels and cocoa pod husks used in this work were collected from a restaurant on the OAU campus and Aba Gbooro village (Ile-Ife, Nigeria), respectively while kola nut pod husks were from a farm (Modakeke, Nigeria). First, each waste was separately sorted to remove dirt present. The agrowastes were cut into small pieces, thoroughly washed with municipal water and sundried for 2 weeks. The pieces of the agrowastes were further dried in an oven at $80^{\circ} \mathrm{C}$ for $48 \mathrm{~h}$ to constant weight [22]. Then, the oven-dried agrowastes were completely combusted to produce ash individually. The resulting ashes were milled into powder in a porcelain mortar and pestle. The to synthesize the CPK, the three ashes from cocoa pod husk, plantain peel and kola nut pod husk were mixed in equal proportions. The ash mixture was heated in a muffle furnace at $300-1100{ }^{\circ} \mathrm{C}$ for $4 \mathrm{~h}[7,22]$. The heat-treated ash was ground to fine powder using porcelain mortar and pestle which was stored in a screwed bottle and kept in a desiccator for further analysis.

\subsection{Characterization of Synthesized CPK Catalyst}

The activity of the calcined CPK was analyzed to establish its suitability as a catalyst. The elemental composition and surface morphology of calcined CPK were analyzed with high resolution scanning electron microscope (AURIGA, Zeiss, Jena, Germany) attached to the EDX spectrometer. To observe the crystalline structure of the sample the diffraction pattern of calcined CPK was documented by an Advance diffractometer-D8 (Bruker AXS, Karlsruhe, Germany). The diffractometer was fitted out a LynxEye position sensitive detector employed with $\mathrm{CuK} \alpha$ radiation source $\left(\lambda \mathrm{K}_{\alpha 1}=1.5406 \AA\right)$. Scanning of CPK was carried out in the region between $4.013^{\circ}-60.0152^{\circ}$ in a continuous mode over 2-theta range. FTIR spectrometer was used to examine the active functional groups present at the active site of the calcined CPK. IR spectra were recorded using the KBr technique on a Nicolet iS10 FTIR spectrometer (Thermo Fischer Scientific, Madison, WI, USA) fitted with attenuated total reflectance (ATR) between $4000 \mathrm{~cm}^{-1}$ and $400 \mathrm{~cm}^{-1}$ range. The pore structure and surface area of the calcined CPK was measured by BET method of physisorption of $\mathrm{N}_{2}$ with a Micromeritics instrument (ASAP 2020, Micromeritics Instrument Corp., Norcross, GA, USA). The BJH method was used to estimate total average pore size and pore volume of the calcined CPK $[18,23,30]$.

\subsection{Blending of Honne, Rubber Seed and Neem Oils}

The blending of honne oil, rubber seed oil and neem oil was done using a $1000 \mathrm{~mL}$ round bottom flask following the method earlier described in our previous report [30]. The mixtures were prepared according to the following volumetric ratios: 20:60:20, 40:40:20, 60:20:20, 20:40:40, 40:20:40, 20:20:60 and 33.3:33.3:33.3 (Table 3). Prior to the blending, each oil was preheated at $60^{\circ} \mathrm{C}$ for $15 \mathrm{~min}$. The preheated oils were blended together in a flask placed on a hot plate and stirred. Each blended oil was further heated 
at $60{ }^{\circ} \mathrm{C}$ for $30 \mathrm{~min}$ on the on a hot plate with stirring to ensure uniform mixing. Physical and chemical properties of the individual oil and each oil blend were measured using the standard methods [58].

\subsection{Model Development for HRNO Blend Transesterification}

In this study, CCRD design was used to model the transesterification of the oil blend with methanol using calcined $\mathrm{CPK}$ as the base catalyst. The range of independent variables investigated were $\mathrm{MeOH}$ : HRNO (6:1-12:1), CPK loading (2-4 wt.\%) and reaction time (2-6 min) with the HRNOB yield as the response. A fractional factorial design with five-level-three-factor was applied to generate 15 set of experimental conditions carried out in batch-wise in a microwave device (Table 9). The axial distance $\alpha$ of each process variable was selected to be 1.414 for orthogonality of the design and to test how repeatable the technique is the center point was repeated five times. The experimental runs were randomized to reduce unexpected variation in the response. To connect the response and the independent variables, multiple regression model was used to fit the experimental data (Equation (2)). The characteristics of the quadratic model was assessed by various statistics. Optimum values of the process variables were determined with Design Expert 10.0 (Stat-Ease Inc., Minneapolis, MN, USA). The condition for optimum biodiesel yield was validated by performing experiment at optimum points of the design variables in triplicate:

$$
R=\mu_{\mathrm{o}}+\mu_{1} A+\mu_{2} B+\mu_{3} C+\mu_{12} A B+\mu_{13} A C+\mu_{23} B C+\mu_{11} A^{2}+\mu_{22} B^{2}+\mu_{33} C^{2}
$$

where, $R$ is the response (HRNOB yield), $\mu_{\mathrm{o}}$ is the intercept term, $\mu_{1}, \mu_{2}$ and $\mu_{3}$ are the coefficients of linear terms. $\mu_{12}, \mu_{13}$, and $\mu_{23}$ are coefficients of the interactive terms, $\mu_{11}, \mu_{22}$ and $\mu_{33}$ are quadratic terms coefficients. $A, B$ and $C$ represent $\mathrm{MeOH}$ : $\mathrm{HRNO}, \mathrm{CPK}$ loading and time, respectively.

Table 9. Experimental design for HRNOB synthesis.

\begin{tabular}{cccc}
\hline \multirow{2}{*}{ Run } & MeOH: HRNO & CPK (wt. \%) & Time (min) \\
\cline { 2 - 4 } & $(\boldsymbol{A})$ & $(B)$ & $(C)$ \\
\hline 1 & 9 & 3 & 1.17157 \\
2 & 12 & 4 & 2 \\
3 & 12 & 2 & 6 \\
4 & 9 & 3 & 4 \\
5 & 9 & 3 & 4 \\
6 & 9 & 3 & 4 \\
7 & 9 & 4.41421 & 4 \\
8 & 6 & 2 & 2 \\
9 & 9 & 3 & 4 \\
10 & 9 & 1.58579 & 4 \\
11 & 9 & 3 & 4 \\
12 & 13.2426 & 3 & 4 \\
13 & 4.75736 & 3 & 4 \\
14 & 9 & 3 & 6.82843 \\
15 & 6 & 4 & 6 \\
\hline
\end{tabular}

\subsection{Esterification of HRNO Blend}

The HRNO blend (20:20:60) had an acid value of $31.97 \mathrm{mg} \mathrm{KOH} / \mathrm{g}$ oil, which is too high for biodiesel synthesis. The pretreatment of this ternary oil blend was carried out in order to reduce the acid value in the oil blend to $<2 \mathrm{mg} \mathrm{KOH} / \mathrm{g}$ oil [57]. The esterification process and the treatment of anhydrous ferric sulphate used as catalyst in this study are according to Falowo et al. [30], which are as follows: temperature of $65^{\circ} \mathrm{C}$, reaction time $2 \mathrm{~h}$, MeOH: Oil blend of $25: 1$ and $10 \mathrm{wt} . \%$ ferric sulfate. 


\subsection{Transesterification of Treated HRNO Blend}

Base catalyzed transesterification of the pretreated HRNO was carried out using a three-neck glass reactor of $500 \mathrm{~mL}$ capacity placed in a modified microwave device (model number MW 7820 Severin Microwave, Sundern, Germany). The microwave device was equipped with an external stirrer fitted with a Teflon rod with two blades and a reflux condenser system. The experiments were conducted as previously described following the experimental design in Table 9 [30]. For each experiment, the microwave device was set at $150 \mathrm{~W}$ and the reaction was performed at specified time according to CCRD. At the completion of the reaction, product mixture was centrifuged for $5 \mathrm{~min}$ at $8000 \mathrm{rpm}$. The biodiesel produced after separation was washed three times with distilled water warmed to $50{ }^{\circ} \mathrm{C}$. The HRNOB yield from the HRNO was determined as described by Equation (3). The quality of the biodiesel obtained was determined to ascertain its suitability as a fuel using methods earlier described our previous study [30]:

$$
\text { HRNOB yield }=\frac{\text { HRNOB produced }(\mathrm{g})}{\text { HRNO blend used }(\mathrm{g})} \times 100
$$

\section{Conclusions}

Blends of cocoa, plantain and kola nut wastes were used as raw materials for catalyst synthesis. The characterization of the CPK catalyst obtained indicates that it could serve as a heterogenous catalyst for transesterification reactions. Particularly, the presence of high level of $\mathrm{K}$ in the CPK makes it an alkaline biobase catalyst. The features of the CPK catalyst developed in this study indicate that it could provide sufficient accessibility to reactants in heterogenous catalyzed-transesterification reactions. Honne, rubber seed and neem oil blend in a volumetric ratio of 20:20:60 was converted into biodiesel by a two-step transesterification process under microwave irradiation and catalyzed by the CPK. The optimum process parameters that gave maximum HRNOB yield of $98.45 \mathrm{wt} . \%$ under microwave irradiation are a reaction time of $6 \mathrm{~min}, \mathrm{CPK}$ loading of $1.158 \mathrm{wt} . \%$ and a $\mathrm{MeOH}$ :oil blend of 12:1. Analysis of fuel quality of the HRNOB produced satisfied the standards specified for biodiesel. Therefore, this study underscores the possible use of mixtures of agrowastes and blend of non-edible oils for biodiesel synthesis in a sustainable manner. The HRNOB produced could be a potential replacement for diesel fuel either to be used directly or partially mixed with diesel fuel in diesel engines.

Author Contributions: Conceptualization, E.B. and T.V.O.; methodology, E.B., T.V.O., O.A.F. and O.P.; software, O.A.F. and E.B.; validation, O.A.F. and E.B.; formal analysis, O.A.F. and O.P.; investigation, O.A.F. and O.P.; resources, E.B. and T.V.O.; data curation, O.A.F. and E.B.; writing-original draft preparation, O.A.F.; writing一review and editing, O.A.F., O.P., E.B. and T.V.O.; visualization, O.A.F. and E.B.; supervision, E.B. and T.V.O.; project administration, E.B.; funding acquisition, E.B. All authors have read and agreed to the published version of the manuscript.

Funding: This research was funded by TETFUND, IBR grant number DESS/RP/Vol.V/2014/4.

Conflicts of Interest: The authors declare no conflict of interest.

\section{References}

1. Sahoo, P.; Das, L. Process optimization for biodiesel production from Jatropha, Karanja and Polanga oils. Fuel 2009, 88, 1588-1594. [CrossRef]

2. Knothe, G.; Razon, L.F. Biodiesel fuels. Prog. Energy Combust. Sci. 2017, 58, 36-59. [CrossRef]

3. Thanh, L.T.; Okitsu, K.; Boi, L.V.; Maeda, Y. Catalytic technologies for biodiesel fuel production and utilization of glycerol: A review. Catalysts 2012, 2, 191-222. [CrossRef]

4. Abdullah, S.H.Y.S.; Hanapi, N.H.M.; Azid, A.; Umar, R.; Juahir, H.; Khatoon, H.; Endut, A. A review of biomass-derived heterogeneous catalyst for a sustainable biodiesel production. Renew. Sustain. Energy Rev. 2017, 70, 1040-1051. [CrossRef]

5. Leung, D.Y.C.; Wu, X.; Leung, M.K.H. A review on biodiesel production using catalyzed transesterification. Appl. Energy 2010, 87, 1083-1095. [CrossRef] 
6. Semwal, S.; Arora, A.K.; Badoni, R.P.; Tuli, D.K. Biodiesel production using heterogeneous catalysts. Bioresour. Technol. 2011, 102, 2151-2161. [CrossRef]

7. Betiku, E.; Akintunde, A.M.; Ojumu, T.V. Banana peels as a biobase catalyst for fatty acid methyl esters production using Napoleon's plume (Bauhinia monandra) seed oil: A process parameters optimization study. Energy 2016, 103, 797-806. [CrossRef]

8. Boey, P.-L.; Maniam, G.P.; Hamid, S.A.; Ali, D.M.H. Utilization of waste cockle shell (Anadara granosa) in biodiesel production from palm olein: Optimization using response surface methodology. Fuel 2011, 90, 2353-2358. [CrossRef]

9. Odude, V.O.; Adesina, A.J.; Oyetunde, O.O.; Adeyemi, O.O.; Ishola, N.B.; Etim, A.O.; Betiku, E. Application of Agricultural Waste-Based Catalysts to Transesterification of Esterified Palm Kernel Oil into Biodiesel: A Case of Banana Fruit Peel Versus Cocoa Pod Husk. Waste Biomass Valoriz. 2017, 1-12. [CrossRef]

10. Liu, D.; Seeburg, D.; Kreft, S.; Bindig, R.; Hartmann, I.; Schneider, D.; Enke, D.; Wohlrab, S. Rice Husk Derived Porous Silica as Support for Pd and $\mathrm{CeO}_{2}$ for Low Temperature Catalytic Methane Combustion. Catalysts 2019, 9, 26. [CrossRef]

11. Nisar, J.; Razaq, R.; Farooq, M.; Iqbal, M.; Khan, R.A.; Sayed, M.; Shah, A.; ur Rahman, I. Enhanced biodiesel production from Jatropha oil using calcined waste animal bones as catalyst. Renew. Energy 2017, 101, 111-119. [CrossRef]

12. Mendonça, I.M.; Machado, F.L.; Silva, C.C.; Junior, S.D.; Takeno, M.L.; de Sousa Maia, P.J.; Manzato, L.; de Freitas, F.A. Application of calcined waste cupuaçu (Theobroma grandiflorum) seeds as a low-cost solid catalyst in soybean oil ethanolysis: Statistical optimization. Energy Convers. Manag. 2019, 200, 112095. [CrossRef]

13. Nath, B.; Das, B.; Kalita, P.; Basumatary, S. Waste to value addition: Utilization of waste Brassica nigra plant derived novel green heterogeneous base catalyst for effective synthesis of biodiesel. J. Clean. Prod. 2019, 239, 118112. [CrossRef]

14. Balajii, M.; Niju, S. Banana peduncle-A green and renewable heterogeneous base catalyst for biodiesel production from Ceiba pentandra oil. Renew. Energy 2020, 146, 2255-2269. [CrossRef]

15. Gohain, M.; Laskar, K.; Paul, A.K.; Daimary, N.; Maharana, M.; Goswami, I.K.; Hazarika, A.; Bora, U.; Deka, D. Carica papaya stem: A source of versatile heterogeneous catalyst for biodiesel production and C-C bond formation. Renew. Energy 2020, 147, 541-555. [CrossRef]

16. Pathak, G.; Das, D.; Rajkumari, K.; Rokhum, L. Exploiting waste: Towards a sustainable production of biodiesel using Musa acuminata peel ash as a heterogeneous catalyst. Green Chem. 2018, 20, 2365-2373. [CrossRef]

17. Adeyi, O. Proximate composition of some agricultural wastes in Nigeria and their potential use in activated carbon production. J. Appl. Sci. Environ. Manag. 2010, 14. [CrossRef]

18. Betiku, E.; Okeleye, A.A.; Ishola, N.B.; Osunleke, A.S.; Ojumu, T.V. Development of a Novel Mesoporous Biocatalyst Derived from Kola Nut Pod Husk for Conversion of Kariya Seed Oil to Methyl Esters: A Case of Synthesis, Modeling and Optimization Studies. Catal. Lett. 2019, 149, 1772-1787. [CrossRef]

19. Osakwe, E.; Ani, I.; Akpan, U.; Olutoye, M. Kolanut pod husk as a biobase catalyst for fatty acid methyl ester production using Thevetia peruviana (Yellow oleander) seed oil. IOP Conf. Ser. 2018, 173, 012008. [CrossRef]

20. Ofori-Boateng, C.; Lee, K.T. The potential of using cocoa pod husks as green solid base catalysts for the transesterification of soybean oil into biodiesel: Effects of biodiesel on engine performance. Chem. Eng. J. 2013, 220, 395-401. [CrossRef]

21. Betiku, E.; Etim, A.O.; Pereao, O.; Ojumu, T.V. Two-step conversion of neem (Azadirachta indica) seed oil into fatty methyl esters using an heterogeneous biomass-based catalyst: An example of cocoa pod husk. Energy Fuels 2017, 31, 6182-6193. [CrossRef]

22. Betiku, E.; Ajala, S.O. Modeling and optimization of Thevetia peruviana (yellow oleander) oil biodiesel synthesis via Musa paradisiacal (plantain) peels as heterogeneous base catalyst: A case of artificial neural network vs. response surface methodology. Ind. Crops Prod. 2014, 53, 314-322. [CrossRef]

23. Etim, A.O.; Betiku, E.; Ajala, S.O.; Olaniyi, P.J.; Ojumu, T.V. Potential of Ripe Plantain Fruit Peels as an Ecofriendly Catalyst for Biodiesel Synthesis: Optimization by Artificial Neural Network Integrated with Genetic Algorithm. Sustainability 2018, 10, 707. [CrossRef]

24. Meneghetti, S.M.P.; Meneghetti, M.R.; Serra, T.M.; Barbosa, D.C.; Wolf, C.R. Biodiesel production from vegetable oil mixtures: Cottonseed, soybean, and castor oils. Energy Fuels 2007, 21, 3746-3747. [CrossRef] 
25. Khalil, I.; Aziz, A.R.A.; Yusup, S.; Heikal, M.; El-Adawy, M. Response surface methodology for the optimization of the production of rubber seed/palm oil biodiesel, IDI diesel engine performance, and emissions. Biomass Convers. Biorefin. 2017, 7, 37-49. [CrossRef]

26. Vinayaka, A.S.; Mahanty, B.; Rene, E.R.; Behera, S.K. Biodiesel production by transesterification of a mixture of pongamia and neem oils. Biofuels 2018. [CrossRef]

27. Milano, J.; Ong, H.C.; Masjuki, H.; Silitonga, A.; Chen, W.-H.; Kusumo, F.; Dharma, S.; Sebayang, A. Optimization of biodiesel production by microwave irradiation-assisted transesterification for waste cooking oil-Calophyllum inophyllum oil via response surface methodology. Energy Convers. Manag. 2018, 158, 400-415. [CrossRef]

28. Miraculas, G.A.; Bose, N.; Raj, R.E. Process parameter optimization for biodiesel production from mixed feedstock using empirical model. Sustain. Energy Technol. Assess. 2018, 28, 54-59.

29. Qiu, F.; Li, Y.; Yang, D.; Li, X.; Sun, P. Biodiesel production from mixed soybean oil and rapeseed oil. Appl. Energy 2011, 88, 2050-2055. [CrossRef]

30. Falowo, O.A.; Oloko-Oba, M.I.; Betiku, E. Biodiesel production intensification via microwave irradiation-assisted transesterification of oil blend using nanoparticles from elephant-ear tree pod husk as a base heterogeneous catalyst. Chem. Eng. Process.-Process Intensif. 2019, 140, 157-170. [CrossRef]

31. Fadhil, A.B.; Al-Tikrity, E.T.; Albadree, M.A. Biodiesel production from mixed non-edible oils, castor seed oil and waste fish oil. Fuel 2017, 210, 721-728. [CrossRef]

32. Sharma, M.; Khan, A.A.; Puri, S.; Tuli, D. Wood ash as a potential heterogeneous catalyst for biodiesel synthesis. Biomass Bioenergy 2012, 41, 94-106. [CrossRef]

33. Lukić, I.; Krstić, J.; Jovanović, D.; Skala, D. Alumina/silica supported K 2 CO 3 as a catalyst for biodiesel synthesis from sunflower oil. Bioresour. Technol. 2009, 100, 4690-4696. [CrossRef] [PubMed]

34. Sing, K.; Everett, D.; Haul, R.; Moscou, L.; Pierotti, L.; Rouquerol, J.; Siemieniewska, T. International union of pure and applied chemistry physical chemistry division reporting physisorption data for gas/soils systems with special reference to the determination of surface area and porosity. Pure Appl. Chem. 1985, 57, 603-619. [CrossRef]

35. Deshmane, V.G.; Adewuyi, Y.G. Mesoporous nanocrystalline sulfated zirconia synthesis and its application for FFA esterification in oils. Appl. Catal. A Gen. 2013, 462, 196-206. [CrossRef]

36. Storck, S.; Bretinger, H.; Maier, W.F. Characterization of micro-and mesoporous solids by physisorption methods and pore-size analysis. Appl. Catal. A Gen. 1998, 174, 137-146. [CrossRef]

37. Knothe, G. Dependence of biodiesel fuel properties on the structure of fatty acid alkyl esters. Fuel Process. Technol. 2005, 86, 1059-1070. [CrossRef]

38. Demirbaş, A. Relationships derived from physical properties of vegetable oil and biodiesel fuels. Fuel 2008, 87, 1743-1748.

39. Wang, Y.; Ou, S.; Liu, P.; Zhang, Z. Preparation of biodiesel from waste cooking oil via two-step catalyzed process. Energy Convers. Manag. 2007, 48, 184-188. [CrossRef]

40. Hamidreza, J.; Nor, A.; Amin, T.-K.; Noshadi, I. Microwave assisted biodiesel production from Jatropha curcas L. seed by two-step in situ process: Optimization using response surface methodology. Bioresour. Technol. 2013, 136, 565-573.

41. Körbahti, B.K.; Rauf, M. Response surface methodology (RSM) analysis of photoinduced decoloration of toludine blue. Chem. Eng. J. 2008, 136, 25-30.

42. Tan, Y.H.; Abdullah, M.O.; Nolasco-Hipolito, C.; Zauzi, N.S.A. Application of RSM and Taguchi methods for optimizing the transesterification of waste cooking oil catalyzed by solid ostrich and chicken-eggshell derived CaO. Renew. Energy 2017, 114, 437-447. [CrossRef]

43. Nayak, M.G.; Vyas, A.P. Optimization of microwave-assisted biodiesel production from Papaya oil using response surface methodology. Renew. Energy 2019, 138, 18-28. [CrossRef]

44. Silitonga, A.; Shamsuddin, A.; Mahlia, T.; Milano, J.; Kusumo, F.; Siswantoro, J.; Dharma, S.; Sebayang, A.; Masjuki, H.; Ong, H.C. Biodiesel synthesis from Ceiba pentandra oil by microwave irradiation-assisted transesterification: ELM modeling and optimization. Renew. Energy 2020, 146, 1278-1291. [CrossRef]

45. Hsiao, M.-C.; Lin, C.-C.; Chang, Y.-H. Microwave irradiation-assisted transesterification of soybean oil to biodiesel catalyzed by nanopowder calcium oxide. Fuel 2011, 90, 1963-1967. [CrossRef]

46. Gude, V.G.; Patil, P.; Martinez-Guerra, E.; Deng, S.; Nirmalakhandan, N. Microwave energy potential for biodiesel production. Sustain. Chem. Process. 2013, 1, 5. [CrossRef] 
47. Ong, H.C.; Masjuki, H.; Mahlia, T.; Silitonga, A.; Chong, W.; Leong, K. Optimization of biodiesel production and engine performance from high free fatty acid Calophyllum inophyllum oil in CI diesel engine. Energy Convers. Manag. 2014, 81, 30-40. [CrossRef]

48. Atabani, A.E.; Silitonga, A.S.; Badruddin, I.A.; Mahlia, T.; Masjuki, H.; Mekhilef, S. A comprehensive review on biodiesel as an alternative energy resource and its characteristics. Renew. Sustain. Energy Rev. 2012, 16, 2070-2093. [CrossRef]

49. Sanford, S.D.; White, J.; Shah, P.; Wee, C.; Valverde, M.; Meier, G. Feedstock and Biodiesel Characteristics Report-2009; Renewable Energy Group: Ames, IA, USA, 2010.

50. Oladipo, B.; Betiku, E. Process optimization of solvent extraction of seed oil from Moringa oleifera: An appraisal of quantitative and qualitative process variables on oil quality using D-optimal design. Biocatal. Agric. Biotechnol. 2019, 20, 101187. [CrossRef]

51. Guillén, M.D.; Cabo, N. Relationships between the Composition of Edible Oils and Lard and the Ratio of the Absorbance of Specific Bands of Their Fourier Transform Infrared Spectra. Role of Some Bands of the Fingerprint Region. J. Agric. Food Chem. 1998, 46, 1788-1793. [CrossRef]

52. Latchubugata, C.S.; Kondapaneni, R.V.; Patluri, K.K.; Virendra, U.; Vedantam, S. Kinetics and Optimization Studies using Response Surface Methodology in Biodiesel Production using Heterogeneous Catalyst. Chem. Eng. Res. Des. 2018, 135, 129-139. [CrossRef]

53. Rabelo, S.N.; Ferraz, V.P.; Oliveira, L.S.; Franca, A.S. FTIR analysis for quantification of fatty acid methyl esters in biodiesel produced by microwave-assisted transesterification. Int. J. Environ. Sci. Dev. 2015, 6, 964. [CrossRef]

54. Soares, I.P.; Rezende, T.F.; Silva, R.C.; Castro, E.V.R.; Fortes, I.C. Multivariate calibration by variable selection for blends of raw soybean oil/biodiesel from different sources using fourier transform infrared spectroscopy (FTIR) spectra data. Energy Fuels 2008, 22, 2079-2083. [CrossRef]

55. Dharma, S.; Masjuki, H.H.; Ong, H.C.; Sebayang, A.H.; Silitonga, A.S.; Kusumo, F.; Mahlia, T.M.I. Optimization of biodiesel production process for mixed Jatropha curcas-Ceiba pentandra biodiesel using response surface methodology. Energy Convers. Manag. 2016, 115, 178-190. [CrossRef]

56. Gimbun, J.; Ali, S.; Kanwal, C.; Shah, L.A.; Ghazali, N.H.M.; Cheng, C.K.; Nurdin, S. Biodiesel production from rubber seed oil using a limestone based catalyst. Adv. Mater. Phys. Chem. 2012, 2, 138-141. [CrossRef]

57. Betiku, E.; Omilakin, O.R.; Ajala, S.O.; Okeleye, A.A.; Taiwo, A.E.; Solomon, B.O. Mathematical modeling and process parameters optimization studies by artificial neural network and response surface methodology: A case of non-edible neem (Azadirachta indica) seed oil biodiesel synthesis. Energy 2014, 72, $266-273$. [CrossRef]

58. AOAC. Official Methods of Analysis of the Association of Official Analytical Chemists; AOAC: Washington, DC, USA, 1990.

(C) 2020 by the authors. Licensee MDPI, Basel, Switzerland. This article is an open access article distributed under the terms and conditions of the Creative Commons Attribution (CC BY) license (http://creativecommons.org/licenses/by/4.0/). 